\title{
Observations of Cloud, Radiation, and Surface Forcing in the Equatorial Eastern Pacific
}

\author{
C. W. Fairall, Taneil Uttal, and Duane Hazen \\ NOAA/Earth System Research Laboratory, Boulder, Colorado \\ JEFFREY HARE \\ Cooperative Institute for Research in Environmental Sciences, University of Colorado, and NOAA/Environmental \\ Technology Laboratory, Boulder, Colorado \\ Meghan F. CRonin \\ NOAA/Pacific Marine Environmental Laboratory, Seattle, Washington \\ NichOLAS BOND \\ Joint Institute for the Study of the Atmosphere and Oceans, University of Washington, and NOAA/Pacific Marine \\ Environmental Laboratory, Seattle, Washington \\ DANA E. VERON \\ College of Marine and Earth Studies, University of Delaware, Newark, Delaware
}

(Manuscript received 7 November 2006, in final form 9 May 2007)

\begin{abstract}
In this paper the authors report on a study of cloud and surface flux processes in the tropical eastern Pacific Ocean based on a series of ship-based cloud and flux measurements made during fall (1999-2002) and spring (2000-02) maintenance cruises along the $95^{\circ}$ and $110^{\circ} \mathrm{W}$ Tropical Atmosphere Ocean (TAO) buoy lines between $8^{\circ} \mathrm{S}$ and $12^{\circ} \mathrm{N}$. The year-to-year and seasonal variabilities of many of the meteorological and oceanic means are relatively small. However, notable seasonal variability is found in the northern branch of the intertropical convergence zone, the north-south sea surface temperature gradient, and heat fluxes north of the equator. In the fall, the strengthening of the north-south SST contrast enhances convective activity (more and deeper clouds, precipitation, southerly inflow) in the area around $6^{\circ} \mathrm{N}, 95^{\circ} \mathrm{W}$; diurnal variations of low cloud fraction were weak. Spring cloud fraction varied significantly over the diurnal cycle with substantially lower cloud fraction during the day south of $5^{\circ} \mathrm{N}$. Relatively low average cloud-base heights around the equator are due to chilling of the marine boundary layer over the cold tongue.

Cloud radiative forcing strongly correlates with cloud fraction; clouds in the observation region cool the surface by about $40 \mathrm{~W} \mathrm{~m}^{-2}$ in both seasons. Cloud forcing estimates from the ship data, the TAO buoys, and International Satellite Cloud Climatology Project (ISCCP) products were combined to form a consensus observation dataset that is compared with the second NCEP reanalysis (NCEP-2) and 40-yr ECMWF Re-Analysis (ERA-40) cloud forcing values. The reanalysis products were within $10 \mathrm{~W} \mathrm{~m}^{-2}$ of the observations for IR cloud forcing but substantially overestimated the solar cloud forcing, particularly in spring.
\end{abstract}

\section{Introduction}

It is generally understood that a substantial part of atmospheric predictability on seasonal and longer time scales is linked to the predictability of the oceans and,

Corresponding author address: C. W. Fairall, Physical Science Division, NOAA/ESRL, 325 Broadway, Boulder, CO 80305.

E-mail: chris.fairall@noaa.gov in particular, sea surface temperatures (SSTs) in the tropics. Coupled modeling of the mean state and the variability of the climate is prone to biases and the tropical oceans are the most troublesome region (Gleckler et al. 2006). Eastern Pacific examples of modeling challenges include the equatorial cold tongue being too cold and too far west, the "double intertropical convergence zone (ITCZ)" with too much precipitation in the southern ITCZ, the misrepresentation of El

DOI: $10.1175 / 2007 J C L I 1757.1$

(C) 2008 American Meteorological Society 
Niño-Southern Oscillation (ENSO) variability, and persistent problems in the South American coastal upwelling zone and its associated stratocumulus clouds (Mechoso et al. 1995; Wang et al. 2005; Wittenberg et al. 2006; Large and Danabasoglu 2006). These biases are partly the result of poorly resolved and poorly parameterized physics in coupled models (Ma et al. 1996; Philander et al. 1996). The importance of the turbulent fluxes can be profoundly illustrated in the investigation of Miller et al. (1992), where a small change in the bulk flux parameterization in the European Centre for Medium-Range Weather Forecasts (ECMWF) model completely changed the modeled climate of the tropics. Recent studies with the Community Climate Model (CCM3) have shown the clear need for improvements in the representation of turbulent (Collins et al. 1997) and radiative fluxes (Wild et al. 1995; Garratt and Prata 1996). Of course, the variability of radiative fluxes at the surface is dominated by clouds, and a major source of uncertainty in general circulation models (GCMs) is the representation of clouds and their interactions with the surface radiative field (Browning 1994; Cess et al. 1995; Menon et al. 2002; Siebesma et al. 2004).

The tropical eastern Pacific is a crucial component of the global climate system, especially as related to its variability in association with ENSO. Coupled model studies (Philander et al. 1996; Li and Philander 1996; Delecluse et al. 1998; Phillips et al. 2006) indicate that SST distributions in this region are sensitive to the radiative effects of marine boundary layer (MBL) clouds. This includes the classical subtropical stratocumulus regimes off the coasts of California and Peru and the equatorial stratocumulus occurring in the region of strong north-south SST gradient around latitudes $85^{\circ}-$ $110^{\circ} \mathrm{W}$. Apart from some notable exceptions (Bond 1992; Yuter and Houze 2000; Hashizume et al. 2002; de Szoeke et al. 2005), direct observations of air-sea interaction processes in this region are rare. For example the recent cloud GCM study by Siebesma et al. (2004) relied principally on satellite data products because "no reliable observations of fluxes are available."

Air-sea fluxes, clouds, and other MBL processes that influence flux variability are a major focus of the U.S. Climate Variability and Predictability (CLIVAR) program (Weller et al. 1999; U.S. CLIVAR Pan American Implementation Panel 2002; Raymond et al. 2004; Bretherton et al. 2004) Pan-American Climate Studies (PACS) and the Eastern Pacific Investigation of Climate Processes in the Coupled Ocean-Atmosphere System (EPIC). As one aspect of this effort, Tropical Ocean Atmosphere (TAO) buoy observations were supplemented with additional sites ands suites of sensors, as well as an enhanced monitoring program of
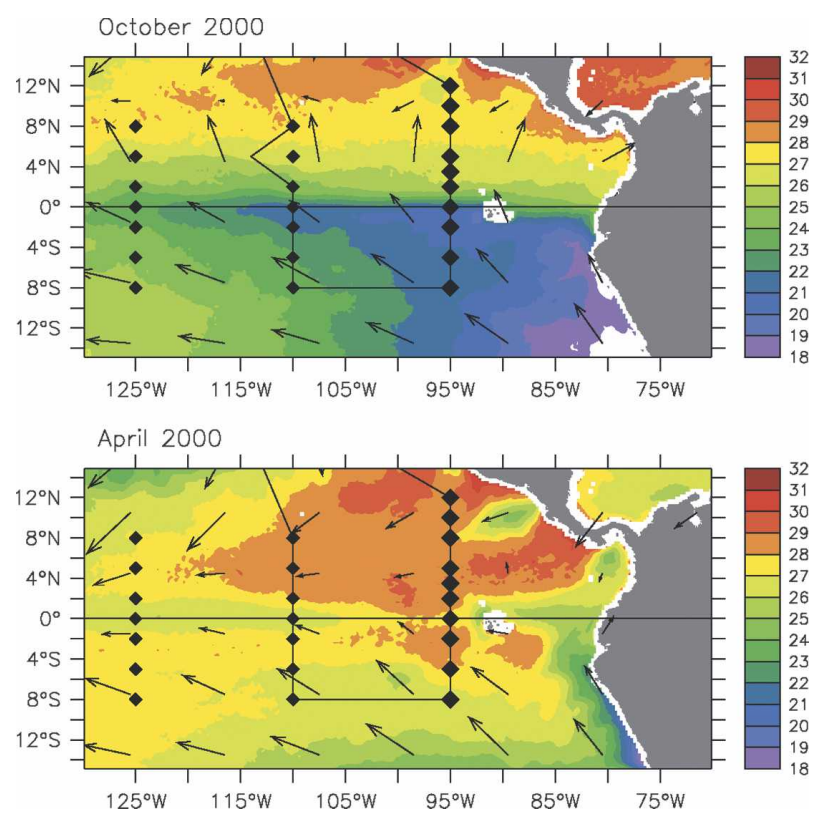

FIG. 1. The EPIC mooring array is shown in relation to the (top) October and (bottom) April 2000 TRMM Microwave Imager SST and QuikSCAT wind fields. Diamonds indicate the locations of TAO buoys; arrows are wind vectors from ERA-40.

high-quality flux, cloud, and profile measurements (Cronin et al. 2002, 2006a,b) from the twice-yearly research vessel cruises that service the $95^{\circ}$ and $110^{\circ} \mathrm{W}$ buoy lines (see Fig. 1).

In this paper we present an analysis of the first four years (1999-2002) of measurements from the shipbased component of the enhanced monitoring program, which was jointly implemented by the NOAA/Earth System Research Laboratory (ESRL) and the NOAA/ Pacific Marine Environmental Laboratory (PMEL). This paper complements two recent papers featuring analysis of the TAO buoy observations along $95^{\circ}$ and $110^{\circ} \mathrm{W}$ : studies of the annual cycle of cloud radiative forcing at the surface (Cronin et al. 2006a) and the annual cycle of sensible and latent heat fluxes (Cronin et al. 2006b). The first paper found disagreements as large as $100 \mathrm{~W} \mathrm{~m}^{-2}$ between buoy radiative flux observations and NWP reanalysis values; the second paper found disagreements of the same order for latent heat flux. The disagreements tended to be largest in spring and fall, which conveniently corresponds to the shipbased observations. The buoy data contain no direct observations of clouds, although some information can be obtained indirectly via the cloud forcing phase diagram (see section 5). The ship data include lidar ceilometer, microwave radiometer, and radar observations of clouds that provide an additional basis for analysis of cloud forcing. 
The remainder of this paper is organized as follows. Details on the ship-based flux and cloud property measurements are given in section 2. The emphasis of the present analysis is on cross-equatorial variability of the mean surface fluxes, the near-surface meteorology, and simple cloud properties (section 3), contrasting the spring and fall seasons. Following a discussion of cloud radiative forcing (section 4), we present a similar crossequatorial analysis of mean cloud properties and cloud forcing (section 5) and compare in situ cloud forcing with satellite and NWP products (section 6). Conclusions are given in section 7 .

\section{The PACS-EPIC enhanced monitoring cruises}

During the twice-yearly maintenance cruises along the $95^{\circ}$ and $110^{\circ} \mathrm{W}$ TAO buoy lines, we implemented a ship-based cloud and flux measurement program to obtain statistics on a critical set of surface, MBL, and low-cloud macrophysical, microphysical, and radiative properties. Deployments on the NOAA ships Ka'imimoana and Ronald H. Brown serve to enhance the monitoring measurements from the TAO buoys. These comprehensive data are expected to be useful for coupled ocean-atmosphere modeling efforts, for MBL and cloud modeling, and to improve satellite retrieval methods for deducing MBL and cloud properties on larger spatial and temporal scales.

The southern end of the $95^{\circ} \mathrm{W}$ line is in the subtropical stratocumulus belt off the west coast of South America, and the $110^{\circ} \mathrm{W}$ line is at the western edge of the PACS region. The northern and southern branches of the ITCZ cross the TAO buoy lines at approximately $8^{\circ}-10^{\circ} \mathrm{N}$ and $5^{\circ}-8^{\circ} \mathrm{S}$ latitudes, respectively. During the Northern Hemisphere spring (from hereon, reference to seasons will be for the Northern Hemisphere), the southern branch of the ITCZ is much weaker than the northern arm and is essentially nonexistent in the fall. For example, examination of the rainfall displayed in Fig. 2 reveals the branched structure of the ITCZ in the spring and also shows the distinct change in rainfall climatology between the seasons. In fall the equatorial cold tongue is well developed at both longitudes, and persistent low stratocumulus and occasional fog are encountered in this area.

\section{a. Methodology}

Two portable flux measurement packages have been developed that can be installed on either ship. The systems include instruments capable of making observations of air-sea turbulent and radiative fluxes, along with ceilometer measurements of cloud base and rawinsonde profiles of wind, temperature, and humidity. All cruises in this analysis carried the ESRL flux system and a basic cloud monitoring package, GPS rawinsondes, a cloud ceilometer, and an automated two-channel microwave radiometer (White et al. 1995; Fairall et al. 1997). On two cruises we also fielded the NOAA Portable Cloud Observatory (NPCO), which features the 35-GHz cloud radar (Moran et al. 1998), a two-channel microwave radiometer (Snider and Hazen 1998), and an upward-looking IR radiometer. A list of the instruments is shown in Table 1, where items 11-13 constitute the NPCO. More information on measurement systems and accuracies can be found in Fairall et al. (1997) and Hare et al. (2005).

We completed seven measurement missions between fall 1999 and fall 2002. The fall 2001 period included the regular TAO-PACS measurement deployment plus the EPIC2001 field program (Raymond et al. 2004). Each mission includes transects of the $95^{\circ}$ and $110^{\circ} \mathrm{W}$ buoy lines between $8^{\circ} \mathrm{S}$ and $12^{\circ} \mathrm{N}$, along with transit legs to and from the experimental area.

\section{b. Database}

For the analysis presented in this paper, data time series from the flux system, cloud ceilometer, and microwave radiometer are processed to 10-min time resolution and integrated to a common time format. The flux database includes turbulent and radiative fluxes and all relevant near-surface bulk meteorological variables. The ceilometer cloud-base height information is processed to 10 -min cloud statistics including vertical cloud fraction and 15\%, 50\% (median), and $85 \%$ heights for the cloud-base cumulative distribution. The microwave radiometer data include column integrated water vapor (IV) and integrated cloud liquid water content $(W)$. (We have created a web-accessible database for our PACS collaborators and other EPIC investigators. Data are archived for public use at ftp://ftp.etl. noaa.gov/user/cfairall/EPIC/epicmonitor/.)

\section{Cross-equatorial and seasonal dependence of ocean forcing and cloud properties}

In this section, we examine the processed datasets from the first seven cruises in the PACS region. By definition, a "climatology/monitoring" project implies multiple measurements in the same region to evaluate variability. In this region, the long-term environmental variability is dominated by El Niño/La Niña cycles, but in the three years of investigations reported here, it is possible to observe only a portion of one cycle. There are significant seasonal differences between our spring 

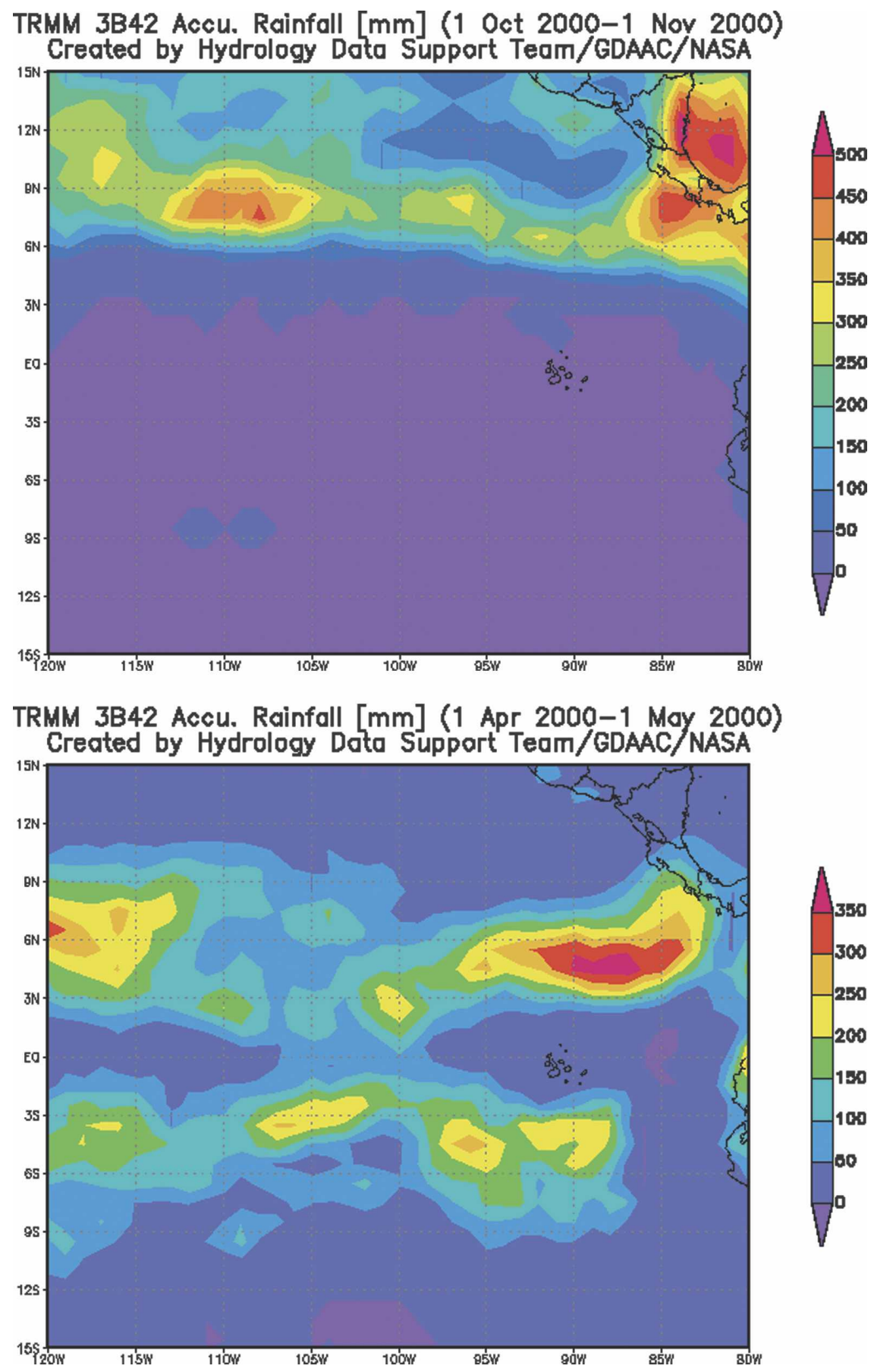

FIG. 2. One-month rainfall accumulations from the TRMM 3B42 rainfall product for (a) spring and (b) fall 2000 cruises.

and fall cruises. There is also some difference between the $110^{\circ}$ and $95^{\circ} \mathrm{W}$ transects. Finally, there is short-term variability associated with the Madden-Julian oscillation, synoptic-scale fluctuations such as easterly waves, and the tropical instability waves (TIW) in the ocean that cause latitudinal displacements of the SST fronts.
An example of the SST and wind fields obtained from the satellite observations for both seasons is shown in Fig. 1. The warm pool south of the equator (associated with the weak southern ITCZ seen in Fig. 2) in spring contrasts sharply with the deep cold tongue and extensive cold band south of the equator in fall. Also note the 
TABLE 1. Instruments deployed and measurements by ESRL for the ship-based cloud/MBL monitoring project.

\begin{tabular}{cll}
\hline \hline Item & \multicolumn{1}{c}{ System } & \multicolumn{1}{c}{ Measurement } \\
\hline 1 & Motion/navigation package & Motion correction for turbulence \\
2 & Sonic anemometer/thermometer & Direct covariance turbulent fluxes \\
3 & IR fast $\mathrm{H}_{2} \mathrm{O} / \mathrm{CO}_{2}$ sensor & Direct covariance moisture/CO $\mathrm{CO}_{2}$ fluxes \\
4 & Mean SST, air temperature/RH & Bulk turbulent fluxes \\
5 & Pyranometer/pyrgeometer & Downward solar and IR radiative flux \\
6 & Ceilometer & Cloud-base height \\
7 & 0.92- or 3-GHz Doppler radar profiler & Cloud-top height, MBL microturbulence \\
8 & Rawinsonde & MBL wind, temperature, humidity profiles \\
9 & 23-, 31-GHz wave radiometer (ARM type: MAILBOX) & Integrated cloud liquid water \\
& & Integrated total water vapor \\
10 & BNL rotating shadowband radiometer & Direct/diffuse solar \\
12 & 35-GHz Doppler cloud radar & Cloud microphysical properties \\
13 & 20, 31, 90 GHz: wave radiometer (ESRL) & Integrated cloud liquid water \\
14 & Upward-pointed IR thermometer & Integrated total water vapor \\
& Ronald $H$. Brown C-band radar & Cloud-base radiative temperature \\
\hline
\end{tabular}

very strong southerly winds at $5^{\circ} \mathrm{N}$ feeding a much stronger northern ITCZ (see Fig. 2) in fall.

In the remainder of this section we will show various quantities of interest computed as one-day averages and averaged further in latitude bins. One-day averages are chosen as a convenience that removes the diurnal cycle and reduces much of the sampling variability. There are some differences in the average properties at $95^{\circ}$ and $110^{\circ} \mathrm{W}$ (see Table 2 ), but the seasonal and latitudinal variations dominate. For basic near-surface bulk meteorological variables the $\mathrm{N}-\mathrm{S}$ or fall-spring spans are typically five times the difference between the $95^{\circ}$ and $110^{\circ}$ latitude lines; for basic measured turbulent and radiative fluxes they are an order of magnitude larger. As a result, we have combined $95^{\circ}$ and $110^{\circ} \mathrm{W}$ data in the following presentation.

\section{a. Meteorological variables and fluxes}

In Fig. 3a, we show an example of the wind components for each cruise to illustrate the variability at daily time scales. Figure $3 \mathrm{~b}$ shows the same data averaged by season: strong southeasterly winds occur south of the equator with a minimum in the easterly component well north of the equator and a clear strengthening of the northerly component approaching the ITCZ in the fall. Wind speed is a maximum (about $7 \mathrm{~m} \mathrm{~s}^{-1}$ ) at the southern end of the study area with a tendency for the spring winds to be stronger.

We have computed the standard deviations of the ensemble daily averages of the environmental variables within each latitude/seasonal bin. The results show small latitudinal variations, which we have summarized

TABLE 2. Standard deviation of selected variables, computed for all three years of cruise data during each season (spring or fall) within a single latitude bin. The values presented are computed from the average variance of all latitude bins. The mean difference between $95^{\circ}$ and $110^{\circ}$ lon is indicated by $X_{95}-X_{110}$.

\begin{tabular}{|c|c|c|c|c|c|c|}
\hline Variable & Symbol & Units & Fall $\sigma$ & Spring $\sigma$ & $X_{95}-X_{110}$ & Measurement height \\
\hline Wind speed & $S$ & $\mathrm{~m} \mathrm{~s}^{-1}$ & 2.5 & 2.5 & -0.7 & $17.5(R B) 16.5(K A) \mathrm{m}$ \\
\hline $\mathrm{N}$ wind computed & $U_{n}$ & $\mathrm{~m} \mathrm{~s}^{-1}$ & 1.5 & 1.4 & -0.8 & $17.5(R B) 16.5(K A) \mathrm{m}$ \\
\hline E wind computed & $U_{e}$ & $\mathrm{~m} \mathrm{~s}^{-1}$ & 2 & 2 & -1.8 & $17.5(R B) 16.5(K A) \mathrm{m}$ \\
\hline Air temperature & $T_{a}$ & ${ }^{\circ} \mathrm{C}$ & 0.77 & 0.42 & -1.1 & $14.8 \mathrm{~m}$ \\
\hline SST & $T_{s}$ & ${ }^{\circ} \mathrm{C}$ & 0.92 & 0.57 & -1.5 & $-20 \mathrm{~cm}$ \\
\hline Specific humidity & $q$ & $\mathrm{~g} \mathrm{~kg}^{-1}$ & 0.65 & 0.7 & -1.2 & $14.8 \mathrm{~m}$ \\
\hline Down solar flux & $R_{\text {sd }}$ & $\mathrm{W} \mathrm{m}^{-2}$ & 56 & 27 & 8 & N/A \\
\hline Down IR flux & $R_{\mathrm{ld}}$ & $\mathrm{W} \mathrm{m}^{-2}$ & 14 & 9.3 & -9.1 & N/A \\
\hline Clear-sky solar flux & $R_{\mathrm{scl}}$ & $\mathrm{W} \mathrm{m}^{-2}$ & 14 & 14 & -8 & - \\
\hline Clear-sky IR flux & $R_{\mathrm{lcl}}$ & $\mathrm{W} \mathrm{m}^{-2}$ & 6.5 & 3.8 & -9.1 & - \\
\hline Sensible heat flux & $H_{s}$ & $\mathrm{~W} \mathrm{~m}^{-2}$ & 2.8 & 3.5 & -0.9 & $17.5(R B) 16.5(K A) \mathrm{m}$ \\
\hline Latent heat flux & $H_{l}$ & $\mathrm{~W} \mathrm{~m}^{-2}$ & 24 & 20 & 2 & $17.5(R B) 16.5(K A) \mathrm{m}$ \\
\hline Cloud fraction & $f$ & - & 0.2 & 0.14 & -0.02 & N/A \\
\hline Cloud-base height & $z_{b}$ & $\mathrm{~m}$ & 190 & 180 & 7 & N/A \\
\hline Precipitable water & $I V$ & $\mathrm{~cm}$ & 0.89 & 0.61 & -0.9 & N/A \\
\hline
\end{tabular}



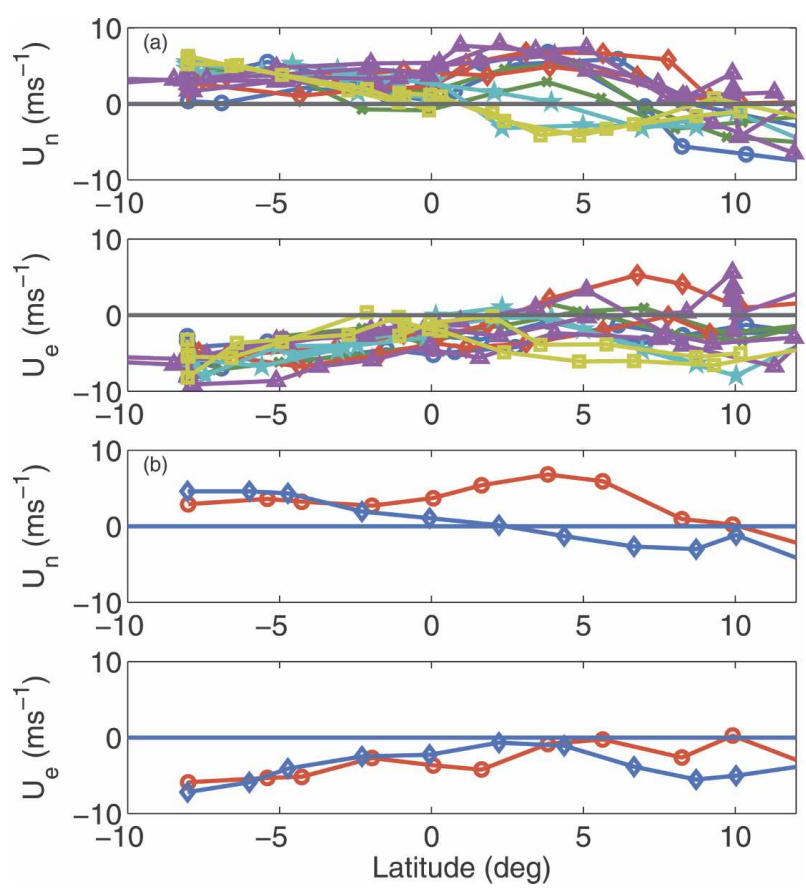

FIG. 3. Wind components: (a) Daily-averaged values, with each symbol representing a single cruise and including both $110^{\circ}$ and $95^{\circ} \mathrm{W}$ longitudinal portions. (top) Meridional $\left(V_{n}\right)$ and (bottom) zonal $\left(U_{e}\right)$. (b) As in (a) but latitude-averaged values. Circle: fall; diamond: spring.

in Table 2. If daily values are statistically independent, the sampling uncertainty at a given bin/season is the standard deviation divided by the square root number of sample days (typically 5-10). In that case, the uncertainties in the individual mean values shown in Fig. 3b and the related plots to follow are the standard deviations given in Table 2 multiplied by approximately onethird. Examination of the 10-min time series for a 20day period at a fixed location during EPIC2001 showed that most of the variables in Table 2 have autocorrelation times of about one day. The exceptions are wind speed and SST, which have autocorrelation times of about five days. However, the ship is typically in one latitude band for approximately two days each visit, so this guideline is still within a factor of 2 . Note that this approach neglects longer time-scale variability such as ENSO.

The seasonal SST cycle is strongest $\left(\sim 6^{\circ} \mathrm{C}\right)$ at the equator and farther south and becomes negligible to the north at about $10^{\circ} \mathrm{N}$ (Fig. 4a). The strong seasonal variation in SST is not mirrored in the latitudinal averaged sea-air temperature difference (Fig. 4b), which is an indication of the boundary layer adjustment processes. There is a slightly positive minimum in sea-air temperature difference $\left(T_{s}-T_{a}\right)$ at or just south of the equator. In fall the maximum in $T_{s}-T_{a}$ (about $2.0^{\circ} \mathrm{C}$ )
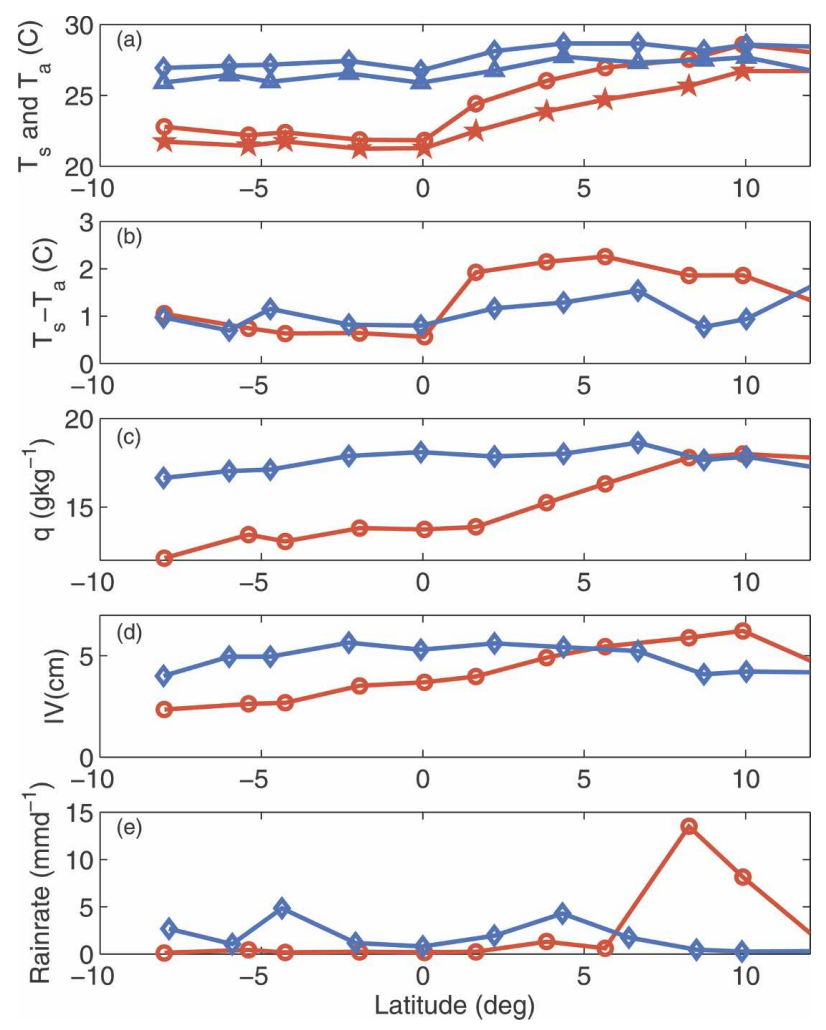

FIG. 4. Latitude-averaged meteorological variables: (a) sea temperature (circle: fall; diamond: spring) and air temperature (star: fall; triangle: spring), (b) sea-air temperature difference, (c) atmospheric specific humidity, (d) column integrated water vapor, and (e) rain rate. In (b)-(e) circles: fall; diamonds: spring.

occurs at $5^{\circ} \mathrm{N}$, which is well downwind of the prevalent SST front around $2^{\circ}-3^{\circ} \mathrm{N}$; in spring the much weaker cold tongue appears to have little effect of the sea-air temperature difference. A relatively strong residual $T_{s}-T_{a}$ exists in the fall (i.e., the fall difference is about double the spring difference north of the equator), which indicates that the surface forcing is greater in the fall and that the MBL response to the surface temperature gradient is not rapid enough to reduce the sea-air temperature difference such as is seen in the spring. Because $T_{s}-T_{a}$ is the result of a thermodynamic balance between surface fluxes, entrainment, and radiative fluxes, it is difficult to explain this response quantitatively without a detailed model study. The boundary layer moisture pattern (as defined by specific humidity and column water vapor) is closely coupled to SST (Fig. 4c). Total column water vapor (Fig. 4d) actually shows a much stronger seasonal variation (i.e., a factor of 2 versus about $30 \%$ for MBL moisture). The upper air is much drier south of about $2^{\circ} \mathrm{N}$ during the fall, presumably because of compensating subsidence in association with deep convection in the northern ITCZ. This has important implications for cloud-top IR radiative cooling. 

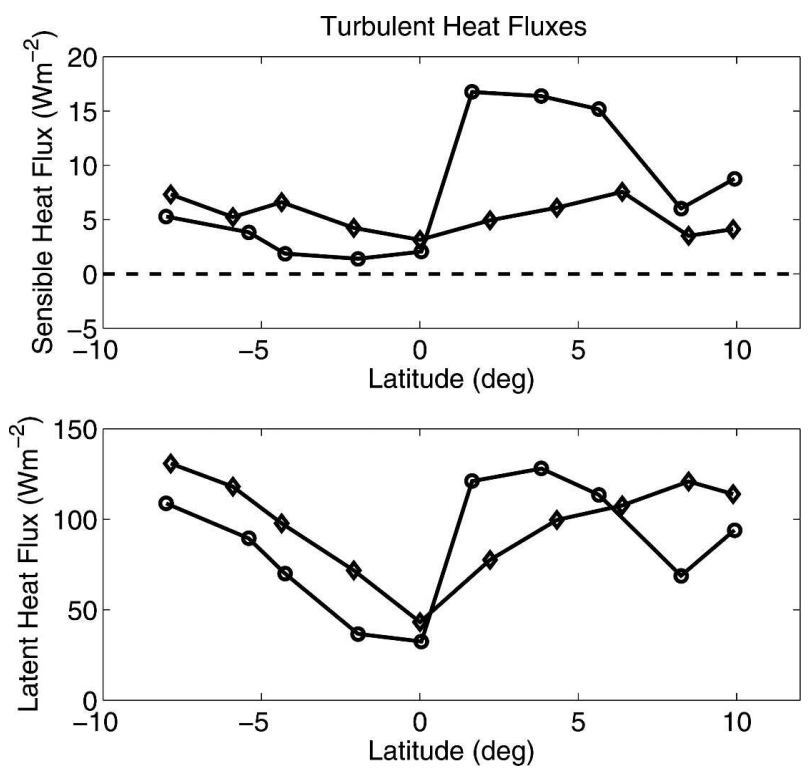

FIG. 5. Latitude-averaged turbulent heat fluxes: (top) Sensible heat and (bottom) latent heat (circles: fall; diamonds: spring).

The latitudinal means of surface sensible and latent heat fluxes are shown in Fig. 5. The turbulent fluxes have minima at, or just south of, the equator, with significantly lower sensible heat fluxes occurring during the spring. Negative sensible heat fluxes are observed episodically, but the overall average is slightly positive. The strong MBL response north of the equator in the fall is the combined result of the greater sea-air temperature difference, accelerating winds, and the large increase in hydrostatic instability. A similar latitudinal signal in the fluxes is reported by de Szoeke et al. (2005) based on EPIC data from fall 2001. Solar flux (Fig. 6) is stronger north of the equator in the spring (approaching summer) and south of the equator in the fall (approaching winter). The normal latitudinal solar zenith angle variation is somewhat masked by the relatively large cloud forcing effects (see section 6). The northern ITCZ is readily apparent as decreased net solar and increased net IR flux around $5^{\circ}-8^{\circ} \mathrm{N}$ during the fall season. The precipitation is most likely undersampled owing to the effects of ship flow distortion on the in situ sensor catchment (Yuter and Parker 2001), but the strong northern ITCZ in fall (about $9^{\circ}-10^{\circ} \mathrm{N}$ ) and the double ITCZ structure in the spring (at approximately $4^{\circ} \mathrm{N}$ and $4^{\circ} \mathrm{S}$ ) are apparent (Fig. 5e). The peak values correspond roughly to the TRMM maps in Fig. 2. However, the TRMM fall rainfall map puts the precipitation maximum around $7.5^{\circ} \mathrm{N}$, which corresponds more closely with the radiative flux than the precipitation measured on the ship.
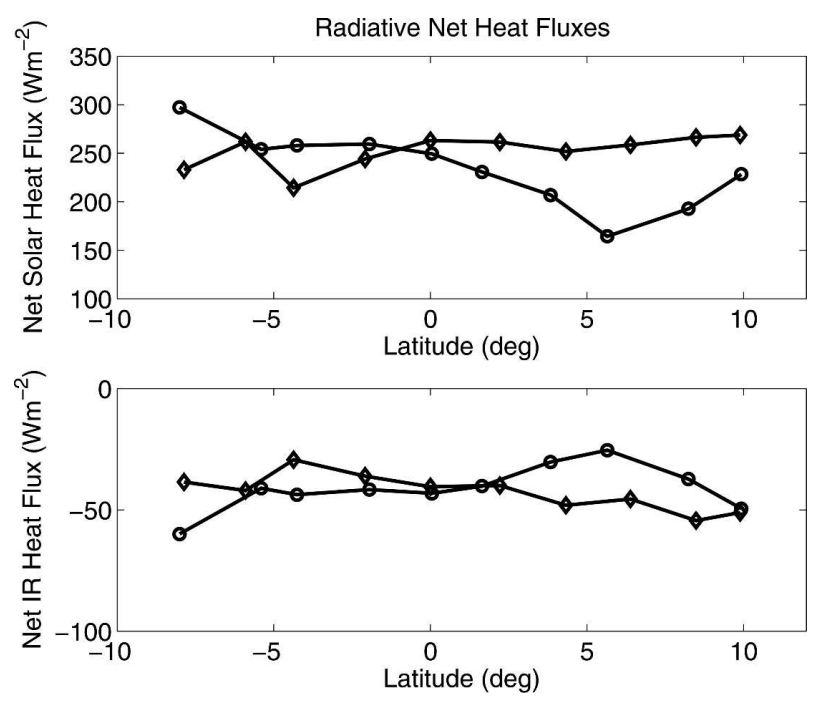

FIG. 6. Latitude-averaged net radiative heat fluxes: (top) Solar flux and (bottom) IR flux (circles: fall; diamonds: spring).

\section{b. Cloud properties}

The low-cloud fraction (Fig. 7) data show the large convective cloud masses in the fall associated with the most active phase of the northern ITCZ, and the location of the peak corresponds well with the radiative results in Fig. 6. The southern ITCZ in spring is also clearly seen at $5^{\circ} \mathrm{S}$, but there seems to be little evidence near $8^{\circ} \mathrm{S}$ of the expected fall increase in cloudiness associated with the edge of the Peruvian stratocumulus region (Norris and Leovy 1994). As displayed in Fig. 7, the 12-h (daytime) and 24-h cloud fraction are plotted

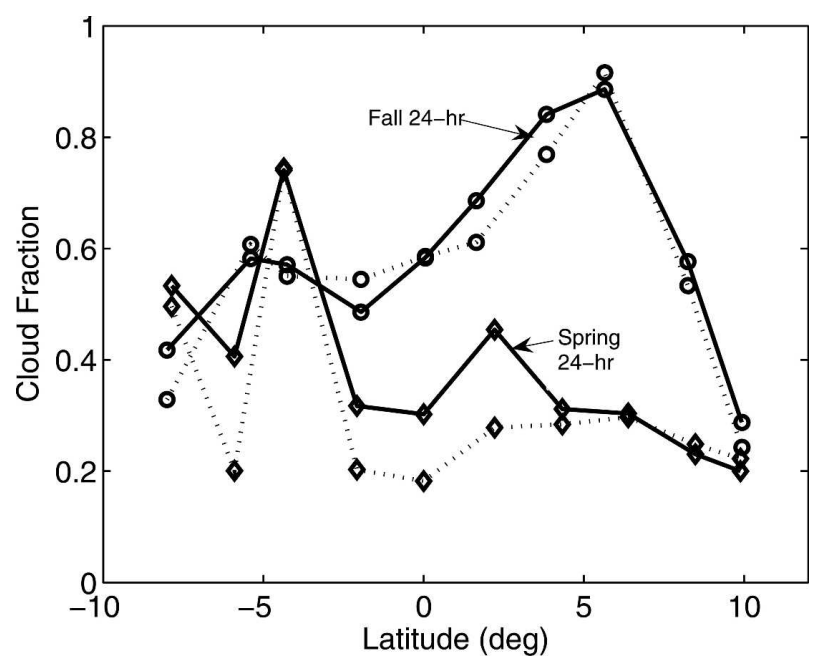

FIG. 7. Latitude-averaged low cloud fraction (circles: fall; diamonds: spring): 24-h average cloud fraction (solid line) and daytime average cloud fraction (dashed line). 
separately as a simple indication of regions with diurnal variation in cloud fraction. Stratocumulus MBL clouds tend to decrease in the local afternoon in response to solar heating, while trade cumulus clouds tend to increase late afternoon in response to strong surface evaporation and instability (Albrecht et al. 1995; Rozendaal et al. 1995; Wood et al. 2002). The results in Fig. 7 are somewhat unanticipated, with only the spring data away from the southern branch of the ITCZ showing significant daytime suppression of marine clouds. This suggests that in the spring the clouds outside the ITCZ are more stratocumulus-like or that the subsidence in those regions has a strong diurnal cycle with an afternoon maximum (Bretherton et al. 2004).

Fair weather broken cumulus clouds are nearly ubiquitous in the undisturbed tropical MBL, and they appear to be part of a self-regulating system that produces low cloud base heights around $600 \mathrm{~m}$ with astoundingly little variation. However, averaging cloud base heights can disguise this, as when tilted trade cumulus clouds are present in the field. In this case, the ceilometer may return high-biased values for "cloud base" which are actually the tilted sides of the clouds. Also, in the presence of deep convection there are often outflow clouds at intermediate heights. Thus, a simple average of ceilometer readings tends to be biased toward higher values than the actual MBL cloud bases (Fig. 8a). Our initial approach to improve the cloud-base height characterization was based on the cumulative height probability distribution of the samples in a 10-min time window. The $50 \%$ point of the cumulative distributions is the median cloud height (i.e., $50 \%$ of the observations have lower cloud base height and 50\% have higher). Similarly, the $15 \%$ point of the distribution defines the height where $15 \%$ of the observed cloud heights are lower and $85 \%$ are higher. We find that the $15 \%$ distribution height tends to reduce the influence of tilted clouds and gives a better estimate of the local boundary-layer (BL) cloud base height. These data suggest seasonal differences only in the northern region (Fig. 8a). Another approach is to examine the probability distribution of base heights at fixed latitude and look for the peak. In this case, we find a peak at $600 \mathrm{~m}$ for most latitudes during both spring and fall seasons (see examples in Fig. 9). There is typically a secondary peak between 1000-1500 m caused by convective cloud-top horizontal spreading at the height of the inversion (Fig. 9a). The latitude dependence of the distribution peaks is shown in Fig. 8b. Exceptions to the common 600-m warm convective cloud base arise for cloud base heights at about $500-550 \mathrm{~m}$ in the core of the ITCZ and when double-peaked distributions (450 and $600 \mathrm{~m})$ occur within $2^{\circ}$ of the equator (Fig. 9b). The additional lower
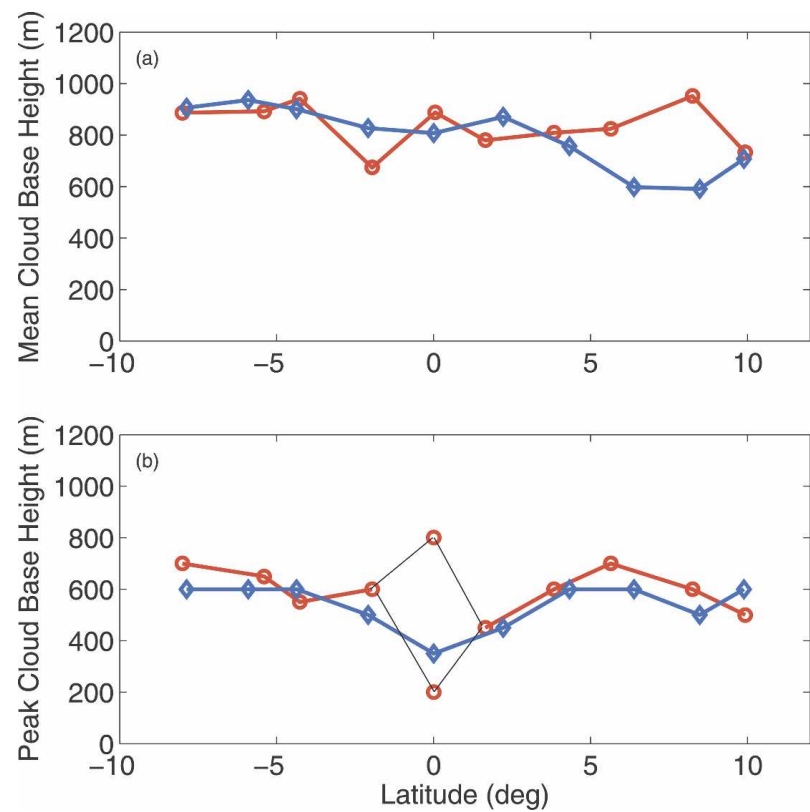

FIG. 8. Latitude-averaged low cloud-base heights (circles: fall; diamonds: spring). (a) The mean of 10 -min values of the $15 \%$ cumulative distribution height and (b) the mean of the peak of the probability distribution for the 10-min values. In the case of the equator, there is no dominant peak and the diagram indicates the range of values (see Fig. 9).

bases near the equator are caused by increased stratification associated with the atmospheric flow over the cold tongue. In the case of the equator during fall, the cloud-base height distribution has no dominant peak, but, instead, is multipeaked from 100 to $800 \mathrm{~m}$ (Fig. 9b). The very low based clouds are consistent with surface cooling or "advection fog," while the relatively high-
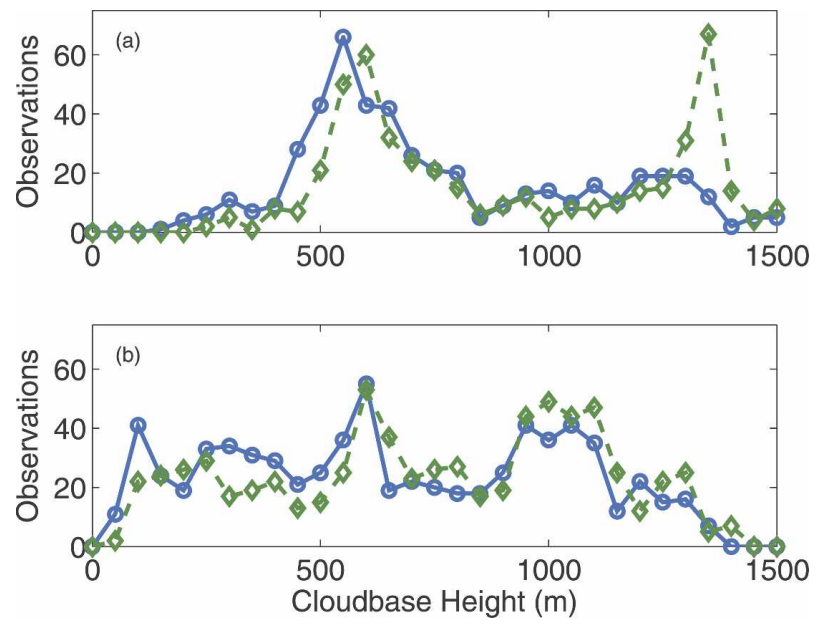

FIG. 9. Histograms of 10-min cloud-base heights (circle: 15\%; diamond: $50 \%$ ) in latitude bins: (a) spring for latitudes between $7^{\circ}$ and $5^{\circ} \mathrm{S}$ and (b) fall for latitudes between $1^{\circ} \mathrm{S}$ and $1^{\circ} \mathrm{N}$. 
based clouds appear to often originate south of the equator and be associated with a decoupled boundary layer.

Measurements of time-averaged cloud liquid water path are shown in Table 3. We have also computed mean liquid water path when clouds are present (approximately equivalent to dividing $W$ by cloud fraction), which gives us the mean liquid when clouds are present $\left(W_{\text {cld }}\right)$. This represents a parameter that corresponds to the "cloudy pixel liquid water" in satellite $W$ retrievals. The higher $W_{\text {cld }}$ values (up to $220 \mathrm{~g} \mathrm{~m}^{-2}$ ) associated with the northern ITCZ in fall are similar to those given by Weng et al. (1997). South of $3^{\circ} \mathrm{N}$ we see the much lower $W_{\text {cld }}$ values (37-137 $\mathrm{g} \mathrm{m}^{-2}$ ) for stratocumulus or tradecumulus clouds. The average $W_{\text {cld }}$ south of $3^{\circ} \mathrm{N}$ in fall is $73 \mathrm{~g} \mathrm{~m}^{-2}$, and for spring it is $93 \mathrm{~g} \mathrm{~m}^{-2}$; daytime cloudy liquid water $\left(W_{\text {cld_s }}\right)$ values are similar.

\section{Cloud radiative forcing}

Cloud forcing $(\mathrm{CF})$ provides an indication of the impact of clouds on the surface energy budget, and this analysis demonstrates the particular emphasis of our observations in the PACS-EPIC region. Cloud forcing is the difference in the observed mean radiative flux versus what the flux would be in the absence of clouds:

$$
\mathrm{CF}_{x}=\left\langle R_{x}\right\rangle-\left\langle R_{x 0}\right\rangle,
$$

where $R$ is the radiative flux, the subscript $x=s$ for solar or $x=l$ for longwave (IR), and the subscript 0 refers to the clear-sky flux. The enhanced monitoring provided direct measurement of clear-sky radiation. From these measurements, clear-sky flux algorithms were tested and tuned for the seasonal variations observed in these regions (see appendix A). A related variable that is often used is the maximum cloud forcing, which is the conditional change in the flux when a cloud is actually present:

$$
\mathrm{MCF}_{x}=\left\langle R_{x 1}\right\rangle-\left\langle R_{x 0}\right\rangle \approx \frac{\mathrm{CF}_{x}}{f}
$$

where $R_{x 1}$ is the radiative flux for overcast conditions and $f$ is cloud fraction. CF averages clear and cloudy periods, but MCF is the difference between overcast (cloud fraction, $f=1.0)$ and clear $(f=0)$ conditions. $\mathrm{MCF}$ is related to the radiative properties of individual clouds and can, in principle, be directly computed from microphysical and radiative variables, while $\mathrm{CF}$ is strongly dependent on whether it is cloudy. MCF also is applied in simple models that use cloud fraction to estimate cloud effects on radiative fluxes (see section 5). For this paper, we will use the CF of the net surface flux
(SCF), which is the quantity most relevant to the surface heat balance of the ocean. Net SCF is downward flux multiplied by $1-\alpha$ (where $\alpha$ is albedo, estimated as $\alpha=0.055$ for solar wavelengths over the sea) or multiplied by the broadband IR emissivity $(\varepsilon)$ of seawater (estimated as 0.97: Fairall et al. 1996).

The CF has seen extensive application as an index of the importance of clouds for the global heat balance [e.g., Ramanathan et al. (1995) for the tropics; Walsh and Chapman (1998) for the Arctic]. This variable yields valuable information about cloud dynamics (Pincus et al. 1997) and is an important tool for diagnosing GCM treatments of cloud/radiative processes. Ramanathan et al. (1995) showed a direct link between surface cloud forcing and oceanic dynamics. Furthermore, Tian and Ramanathan (2002) have shown that $\mathrm{CF}$ is much more directly linked to atmospheric regional dynamics and moisture transports than surface turbulent fluxes.

Cloud forcing can be inferred globally using satellite data at the top of the atmosphere (TOA: Ramanathan et al. 1989) and it can be determined more indirectly from surface data. For SCF, the surface-based methods are more direct and more accurate, but provide limited sampling. Previous studies in the tropics have shown that the heavy water vapor burden in the boundary layer partially masks the longwave (LW) signal from clouds, and SCF is dominated by the solar flux, as LW SCF is about 5 to $15 \mathrm{~W} \mathrm{~m}^{-2}$ while shortwave (SW) SCF ranges from -50 to $-90 \mathrm{~W} \mathrm{~m}^{-2}$ (Stephens and Webster 1981). In subtropical stratocumulus regimes, the solar component is more nearly balanced by the LW component and the total SCF is perhaps closer to $-30 \mathrm{~W} \mathrm{~m}^{-2}$.

This SW versus LW compensating effect depends strongly on latitude and season. Tropical regions have the strongest solar cloud forcing, while polar areas tend to have the strongest relative IR cloud forcing. In the upper midlatitude storm track, total SCF tends to be small because the solar and IR components approximately cancel.

\section{Cloud forcing analysis}

In this section we will examine two aspects of SCF in the eastern equatorial Pacific: the seasonality of SCF (similar to the other atmospheric properties presented in section 3) and the mean dependence of SCF on cloud fraction.

The latitudinal dependence of clear-sky net fluxes is shown in Fig. 10. The counterintuitive asymmetry about the equator for the clear-sky solar flux is caused by the time of year of the observations (see comment about seasonal variations in column water vapor in section 4). 
TABLE 3. Mean ESRL observations along $95^{\circ}$ and $110^{\circ} \mathrm{W}$.

\begin{tabular}{|c|c|c|c|c|c|c|c|c|c|c|c|}
\hline \multirow[b]{2}{*}{ Obs } & \multicolumn{11}{|c|}{ Lat $\left(^{\circ}\right)$} \\
\hline & Units & -8.0 & -6.0 & -4.0 & -2.0 & 0.0 & 2.0 & 4.0 & 6.0 & 8.0 & 10.0 \\
\hline \multicolumn{12}{|c|}{ Fall 1999-2002 } \\
\hline$U_{n}$ & $\mathrm{~m} \mathrm{~s}^{-1}$ & 2.9 & 3.6 & 3.2 & 2.7 & 3.7 & 5.4 & 6.8 & 5.9 & 1.0 & 0.2 \\
\hline$U_{e}^{n}$ & $\mathrm{~m} \mathrm{~s}^{-1}$ & -5.9 & -5.3 & -5.1 & -2.7 & -3.7 & -4.2 & -0.8 & -0.3 & -2.6 & 0.2 \\
\hline$T_{s}$ & ${ }^{\circ} \mathrm{C}$ & 22.8 & 22.2 & 22.4 & 21.9 & 21.8 & 24.4 & 26.0 & 27.0 & 27.5 & 28.6 \\
\hline$T_{a}$ & ${ }^{\circ} \mathrm{C}$ & 21.7 & 21.4 & 21.8 & 21.2 & 21.3 & 22.5 & 23.9 & 24.7 & 25.7 & 26.7 \\
\hline$q$ & $\mathrm{~g} \mathrm{~kg}^{-1}$ & 12.1 & 13.4 & 13.1 & 13.8 & 13.7 & 13.9 & 15.2 & 16.3 & 17.8 & 18.0 \\
\hline IV & $\mathrm{cm}$ & 2.3 & 2.6 & 2.7 & 3.5 & 3.7 & 4.0 & 4.9 & 5.5 & 5.9 & 6.2 \\
\hline Rain & $\mathrm{mm} \mathrm{d}^{-1}$ & 0.1 & 0.4 & 0.2 & 0.2 & 0.2 & 0.2 & 1.3 & 0.6 & 13.5 & 8.1 \\
\hline$H_{s}$ & $\mathrm{~W} \mathrm{~m}{ }^{-2}$ & 5.3 & 3.8 & 1.9 & 1.4 & 2.1 & 16.8 & 16.4 & 15.2 & 6.0 & 9.6 \\
\hline$H_{l}$ & $\mathrm{~W} \mathrm{~m}^{-2}$ & 109 & 89 & 70 & 37 & 32 & 121 & 128 & 114 & 69 & 89 \\
\hline$R_{\mathrm{sd}}$ & $\mathrm{W} \mathrm{m}^{-2}$ & 313 & 267 & 271 & 273 & 262 & 243 & 218 & 173 & 207 & 252 \\
\hline$R_{\mathrm{ld}}$ & $\mathrm{W} \mathrm{m}^{-2}$ & 375 & 392 & 389 & 389 & 385 & 399 & 421 & 431 & 426 & 422 \\
\hline$R_{\text {lnet }}$ & $\mathrm{W} \mathrm{m}^{-2}$ & -60 & -41 & -44 & -42 & -43 & -40 & -30 & -25 & -37 & -50 \\
\hline$R_{\mathrm{scl}}$ & $\mathrm{W} \mathrm{m}^{-2}$ & 351 & 340 & 345 & 331 & 323 & 318 & 306 & 302 & 291 & 326 \\
\hline$R_{\mathrm{lcl}}^{\mathrm{scl}}$ & $\mathrm{W} \mathrm{m}^{-2}$ & 348 & 362 & 354 & 355 & 357 & 366 & 380 & 395 & 404 & 412 \\
\hline$z_{b} 15 \%$ & $\mathrm{~m}$ & 887 & 893 & 941 & 674 & 888 & 780 & 809 & 825 & 951 & 730 \\
\hline$z_{b}$ peak & $\mathrm{m}$ & 700 & 650 & 550 & 600 & 400 & 450 & 600 & 700 & 600 & 500 \\
\hline Cloud $f$ & & 0.42 & 0.58 & 0.57 & 0.49 & 0.58 & 0.69 & 0.84 & 0.89 & 0.58 & 0.25 \\
\hline Cloud_s $f$ & & 0.31 & 0.59 & 0.52 & 0.56 & 0.61 & 0.62 & 0.72 & 0.91 & 0.50 & 0.27 \\
\hline Trans_sol & & 0.89 & 0.79 & 0.79 & 0.83 & 0.81 & 0.76 & 0.71 & 0.57 & 0.71 & 0.77 \\
\hline$W$ & $\mathrm{~g} \mathrm{~m}^{-2}$ & 32 & 58 & 33 & 39 & 44 & 54 & 74 & 106 & 176 & 60 \\
\hline$W_{\text {cld }}$ & $\mathrm{g} \mathrm{m}^{-2}$ & 45 & 84 & 60 & 55 & 62 & 135 & 85 & 135 & 220 & 54 \\
\hline$W_{\text {cld s }}$ & $\mathrm{g} \mathrm{m}^{-2}$ & 35 & 89 & 50 & 39 & 48 & 159 & 81 & 144 & 222 & 60 \\
\hline $\mathrm{CF}_{\mathrm{sl}}$ & $\mathrm{W} \mathrm{m}^{-2}$ & -37 & -69 & -70 & -55 & -58 & -71 & -84 & -123 & -79 & -70 \\
\hline $\mathrm{MCF}_{\mathrm{sl}}$ & $\mathrm{W} \mathrm{m}^{-2}$ & -118 & -116 & -133 & -98 & -94 & -114 & -117 & -135 & -160 & -257 \\
\hline $\mathrm{CF}_{\mathrm{ir}}$ & $\mathrm{W} \mathrm{m}^{-2}$ & 26 & 30 & 33 & 32 & 27 & 32 & 40 & 35 & 21 & 10 \\
\hline $\mathrm{MC}_{\mathrm{fir}}$ & $\mathrm{W} \mathrm{m}^{-2}$ & 63 & 51 & 58 & 67 & 46 & 47 & 47 & 40 & 37 & 39 \\
\hline \multicolumn{12}{|c|}{ Spring $2000-02$} \\
\hline$U_{n}$ & $\mathrm{~m} \mathrm{~s}^{-1}$ & 4.6 & 4.6 & 4.3 & 1.9 & 1.1 & 0.1 & -1.3 & -2.7 & -3.0 & -1.2 \\
\hline$U_{e}^{n}$ & $\mathrm{~m} \mathrm{~s}^{-1}$ & -7.2 & -5.9 & -4.1 & -2.5 & -2.3 & -0.7 & -1.1 & -3.8 & -5.5 & -5.0 \\
\hline$T_{s}$ & ${ }^{\circ} \mathrm{C}$ & 26.9 & 27.1 & 27.1 & 27.4 & 26.7 & 27.9 & 29.0 & 28.8 & 28.3 & 28.6 \\
\hline$T_{a}$ & ${ }^{\circ} \mathrm{C}$ & 25.9 & 26.4 & 26.0 & 26.5 & 25.9 & 26.8 & 27.7 & 27.3 & 27.5 & 27.7 \\
\hline$q$ & $\mathrm{~g} \mathrm{~kg}^{-1}$ & 16.6 & 17.0 & 17.1 & 17.9 & 18.1 & 17.9 & 18.0 & 18.6 & 17.7 & 17.8 \\
\hline IV & $\mathrm{cm}$ & 4.0 & 5.0 & 5.0 & 5.6 & 5.3 & 5.6 & 5.4 & 5.2 & 4.1 & 4.2 \\
\hline Rain & $\mathrm{mm} \mathrm{d}^{-1}$ & 2.7 & 1.0 & 4.8 & 1.2 & 0.8 & 1.9 & 4.3 & 1.7 & 0.5 & 0.3 \\
\hline$H_{s}$ & $\mathrm{~W} \mathrm{~m}{ }^{-2}$ & 7.3 & 5.2 & 6.6 & 4.2 & 3.1 & 4.9 & 6.1 & 7.6 & 3.5 & 4.1 \\
\hline$H_{l}$ & $\mathrm{~W} \mathrm{~m}^{-2}$ & 131 & 118 & 98 & 72 & 43 & 78 & 100 & 108 & 121 & 114 \\
\hline$R_{\mathrm{sd}}$ & $\mathrm{W} \mathrm{m}^{-2}$ & 245 & 276 & 226 & 248 & 277 & 275 & 265 & 272 & 280 & 283 \\
\hline$R_{\mathrm{ld}}$ & $\mathrm{W} \mathrm{m}^{-2}$ & 418 & 415 & 431 & 423 & 416 & 427 & 422 & 422 & 411 & 418 \\
\hline$R_{\text {lnet }}$ & $\mathrm{W} \mathrm{m}^{-2}$ & -39 & -42 & -29 & -36 & -40 & -40 & -48 & -46 & -54 & -51 \\
\hline$R_{\mathrm{scl}}$ & $\mathrm{W} \mathrm{m}^{-2}$ & 297 & 312 & 308 & 310 & 319 & 319 & 319 & 322 & 326 & 328 \\
\hline$R_{\mathrm{lcl}}$ & $\mathrm{W} \mathrm{m}^{-2}$ & 400 & 404 & 403 & 408 & 405 & 409 & 416 & 416 & 410 & 413 \\
\hline$z_{b} 15 \%$ & $\mathrm{~m}$ & 906 & 936 & 901 & 827 & 808 & 871 & 757 & 598 & 591 & 707 \\
\hline$z_{b}$ peak & $\mathrm{m}$ & 600 & 600 & 600 & 500 & 350 & 450 & 600 & 600 & 500 & 600 \\
\hline Cloud $f$ & & 0.53 & 0.41 & 0.74 & 0.32 & 0.30 & 0.45 & 0.31 & 0.30 & 0.23 & 0.20 \\
\hline Cloud_s $f$ & & 0.52 & 0.15 & 0.73 & 0.22 & 0.20 & 0.27 & 0.29 & 0.32 & 0.23 & 0.21 \\
\hline Trans_sol & & 0.83 & 0.88 & 0.73 & 0.80 & 0.87 & 0.86 & 0.83 & 0.84 & 0.86 & 0.86 \\
\hline$W$ & $\mathrm{~g} \mathrm{~m}^{-2}$ & 62 & 45 & 40 & 36 & 27 & 34 & 35 & 35 & 36 & 28 \\
\hline$W_{\text {cld }}$ & $\mathrm{g} \mathrm{m}^{-2}$ & 124 & 123 & 67 & 137 & 37 & 73 & 70 & 64 & 123 & 38 \\
\hline$W_{\text {cld_s }}$ & $\mathrm{g} \mathrm{m}^{-2}$ & 107 & 61 & 75 & 178 & 42 & 95 & 197 & 146 & 205 & 168 \\
\hline $\mathrm{CF}_{\mathrm{sl}}$ & $\mathrm{W} \mathrm{m^{-2 }}$ & -49 & -35 & -78 & -52 & -50 & -46 & -52 & -48 & -44 & -43 \\
\hline $\mathrm{MCF}_{\mathrm{sl}}$ & $\mathrm{W} \mathrm{m}^{-2}$ & -94 & -225 & -107 & -236 & -250 & -156 & -180 & -149 & -188 & -202 \\
\hline $\mathrm{CF}_{\mathrm{ir}}$ & $\mathrm{W} \mathrm{m}^{-2}$ & 18 & 11 & 28 & 15 & 11 & 18 & 6 & 6 & 1 & 4 \\
\hline $\mathrm{MC}_{\mathrm{fir}}$ & $\mathrm{W} \mathrm{m^{-2 }}$ & 34 & 27 & 38 & 48 & 38 & 39 & 19 & 19 & 5 & 22 \\
\hline
\end{tabular}



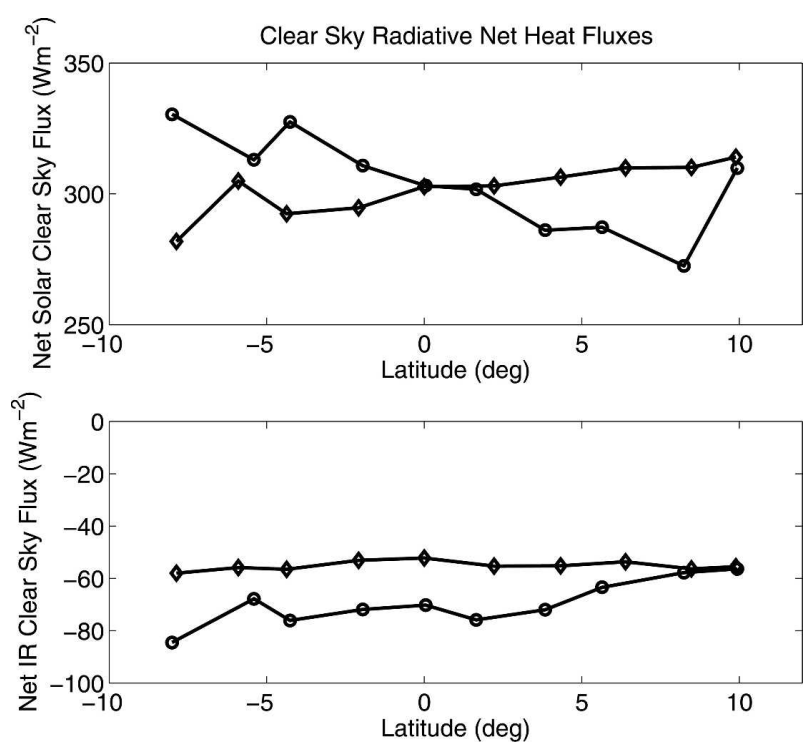

FIG. 10. Latitude-averaged net clear-sky radiative heat fluxes using the models described in appendix A: (top) solar flux and (bottom) IR flux (circles: fall; diamonds: spring). The strange bump at $10^{\circ} \mathrm{N}$ in the fall is caused by observations in the EPIC2001 project that occurred almost two months earlier than the typical fall monitoring cruise.

The more negative clear-sky net IR flux in the fall is caused by the lower atmospheric water vapor during that season. The slightly stronger latitudinal variation of net IR flux in the fall is associated with stronger variations in atmospheric temperature and water vapor. The average of the two seasonal curves gives a net solar clear-sky flux of about $300 \mathrm{~W} \mathrm{~m}^{-2}$ and a net IR clearsky flux of $-68 \mathrm{~W} \mathrm{~m}^{-2}$ north and $-78 \mathrm{~W} \mathrm{~m}^{-2}$ south of the equator. Based on Earth Radiation Budget Experiment (ERBE) data, Tian and Ramanathan (2002) report annual averages for solar flux in the range 270$275 \mathrm{~W} \mathrm{~m}^{-2}$ and IR flux of about $-60 \mathrm{~W} \mathrm{~m}^{-2}$ in the north and $-80 \mathrm{~W} \mathrm{~m}^{-2}$ in the south. Our results are not annual averages, so the significance of the similarities is limited without further study.

The mean SCF for both solar and IR is shown in Fig. 11 for both SW and LW fluxes; the most obvious seasonal SCF difference is the larger magnitudes associated with greater cloudiness in the northern ITCZ. Using the cloud fraction from Fig. 7, we have computed the maximum surface cloud forcing (MSCF), and this is illustrated in Fig. 12. Here we used the 24-h cloud fraction for IR flux and the clear-sky solar-flux-weighted cloud fraction for solar flux. The 24-h cloud fraction does not correlate well with daily SW SCF and, in the case of the mean day-night differences in $f$, may lead to biases in solar MSCF. Because the daily average solar flux is relatively sensitive to cloudiness around local

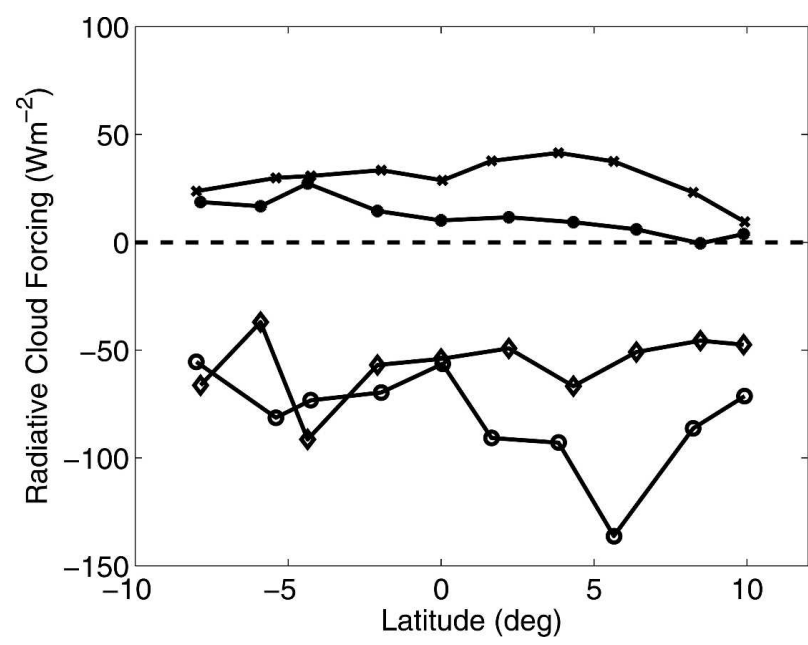

FIG. 11. Latitude-averaged radiative surface SCF: fall IR flux (times signs), spring IR flux (closed circles), fall solar flux (open circles), and spring solar flux (diamonds).

noon, we find that the clear-sky solar-weighted cloud fraction provides a better representation than the daytime $f$. For all latitudes, the IR MSCF is about $15 \mathrm{~W} \mathrm{~m}^{-2}$ lower in spring than in fall.

At a given location SW and LW SCF tend to be highly correlated. The relationship between them can be illustrated with the cloud forcing phase diagram (Hare et al. 2005; Cronin et al. 2006a). When the slope of the line is one, net SFC is zero (i.e., SW cancels LW). In the tropics, SW SFC dominates LW SFC (Tian and Ramanathan 2002), while in polar regions LW dominates (Intrieri et al. 2002). The daily values from this study plotted on the SCF phase diagram (Fig. 13) pro-

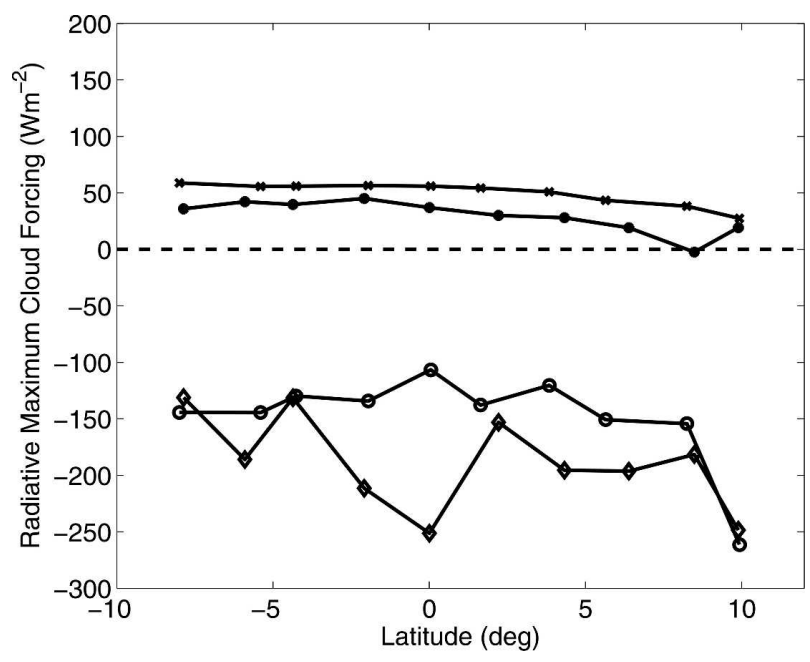

FIG. 12. Latitude-averaged radiative surface maximum SCF computed via Eq. (2): fall IR flux (times signs), spring IR flux (closed circles), fall solar flux (open circles), and spring solar flux (diamonds). 


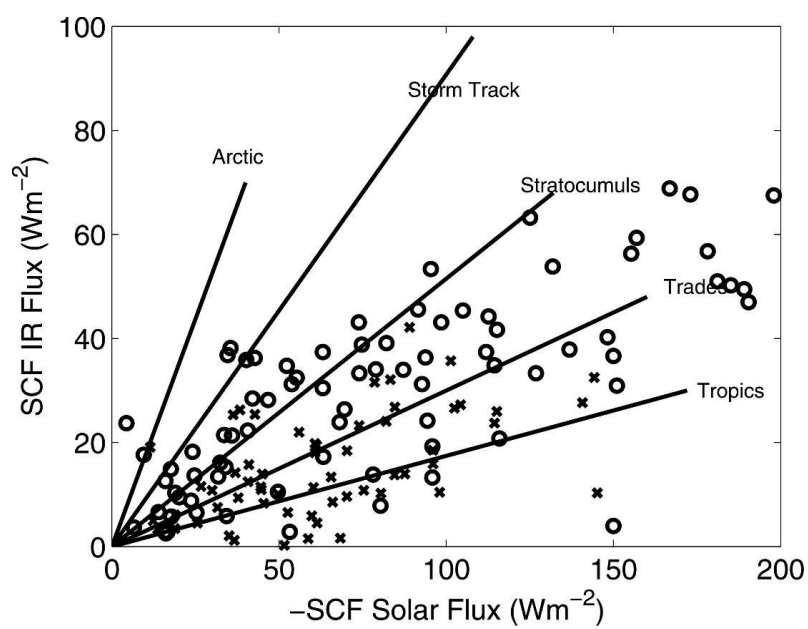

FIG. 13. Cloud forcing phase diagram showing the balance of solar and IR SCF in different climate zones (circles: fall; times signs: spring). An ensemble of individual days in a particular region tend to lie along a line where values near zero from small cloud fraction and values near the maximum are for cloud fraction near 1.0.

vide a striking contrast to the typical behavior in most of ESRL's 11 other tropical cruises (Fairall et al. 2003; Hare et al. 2005). Rather than tending to lie near a single characteristic line, the PACS-EPIC data are scattered from tropical to storm track lines. This clearly indicates that all three principal climate zones (tropical, trade wind, and stratocumulus) are encountered within $10^{\circ}$ of the equator in the eastern Pacific. From this figure, we interpret that the spring has a more tropical signature while the fall period is biased toward trade wind and stratocumulus behavior (consistent with the higher spring SSTs in Fig. 1). The deep convective events in the fall often have very strong cold-air downdrafts that lead to sharp reductions in the near-surface air temperature, which might invalidate the simplistic representation of the IR clear-sky flux.

Of course, cloud forcing depends on cloud fraction. In the simplest case, each cloud's radiative properties are similar to all others, and then CF depends upon the number of clouds in the field. Thus, the radiative flux at the surface can be written

$$
R_{x}=R_{x 0}+f \times \mathrm{MCF}_{x}=(1-f) R_{x 0}+f R_{x 1} .
$$

This approach forms the basis for simple treatments of fractional cloudiness (Hartmann et al. 1992). For solar flux, nonlinear dependencies on vertical $f$ are common (Katsaros 1990; Grant and Hignett 1998). In addition, hemispherically averaged cloud fraction or cloud fraction at the solar zenith angle (White et al. 1996) has also been used. Thus, a linear dependence of CF on cloud fraction implies that such simple models are applicable.

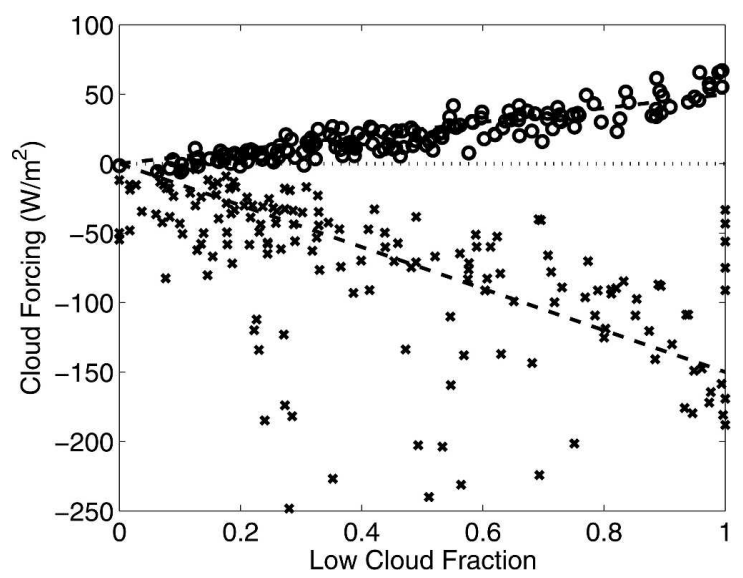

FIG. 14. Daily-averaged SCF as a function of cloud fraction (circle: IR; times signs: solar). The solid lines represent nominal MSCF values of $50 \mathrm{~W} \mathrm{~m}^{-2}$ for IR and $-150 \mathrm{~W} \mathrm{~m}^{-2}$ for solar fluxes.

Here we illustrate this dependence using the dailyaveraged solar and IR fluxes with a 24-h-averaged (for IR) or daytime-averaged (for solar) cloud fraction (Fig. 14). For IR flux, a linear regression gives $\mathrm{MSCF}_{l}=50 \mathrm{~W} \mathrm{~m}^{-2}$. However, a second-order fit gives a linear term of $33 \mathrm{~W} \mathrm{~m}^{-2}$ and a quadratic coefficient of $20 \mathrm{~W} \mathrm{~m}^{-2}$. Thus, for low cloud fractions IR MSCF is less than for high cloud fractions (i.e., 33 versus $33+$ $30=53 \mathrm{~W} \mathrm{~m}^{-2}$ ). For solar flux, the data are too scattered to determine nonlinearity, but a linear regression results in $\mathrm{MSCF}_{s}=-135 \mathrm{~W} \mathrm{~m}^{-2}$.

Figure 15 shows the results of averaging the daily values into bins of cloud fraction where we separate spring (74 days) and fall (86 days) cruises. This figure clearly shows lower LW SCF in the spring than in the

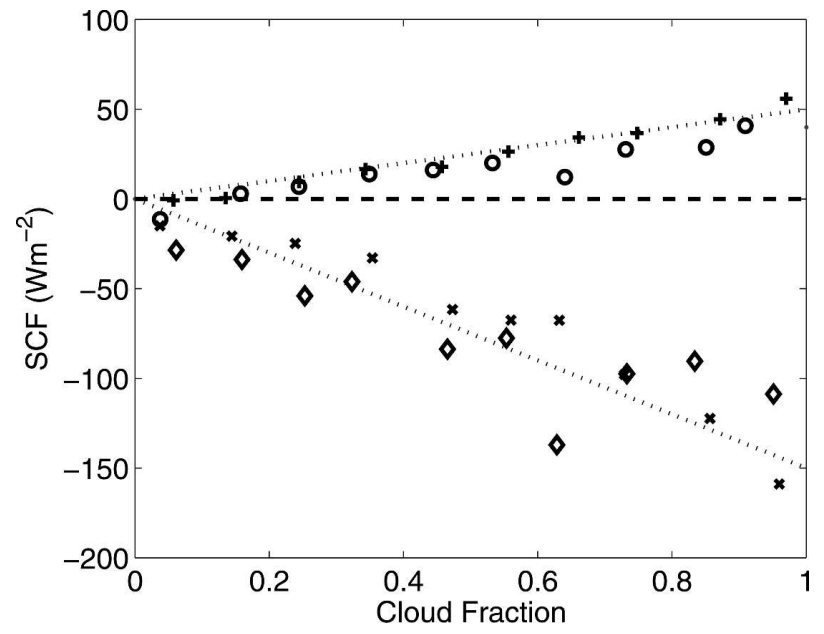

FIG. 15. As in Fig. 11 but the daily data have been averaged in bins of cloud fraction: spring IR (circles), fall IR (pluses), spring solar (diamonds), and fall solar (times signs). 
fall. For cloud fraction less than 0.5 , the fall SW SCF values are smaller in magnitude, but slightly larger for high cloud fractions (greater than 0.7). This is qualitatively consistent with the lower cloudy liquid water path values found south of $3^{\circ} \mathrm{N}$ and the larger values north of $6^{\circ} \mathrm{N}$ in fall versus spring (see the discussion at the end of section 5). Therefore, for solar SCF there are some seasonal differences, particularly north of the equator, not entirely attributable to cloud fraction but are probably associated with the actual liquid water content of the clouds (see discussion at the end of section 3). Linear regressions to these data imply IR MSCF of $53 \mathrm{~W} \mathrm{~m}^{-2}$ in fall and $40 \mathrm{~W} \mathrm{~m}^{-2}$ in spring, with solar MSCF values of $-141 \mathrm{~W} \mathrm{~m}^{-2}$ in fall and $-127 \mathrm{~W} \mathrm{~m}^{-2}$ in spring. Averaging in this form has removed much of the apparent nonlinearity from Fig. 14, suggesting that it was partly caused by mixing spring and fall data.

\section{Intercomparisons of in situ radiative fluxes with NWP and satellite values}

In this section we examine different sources of data for estimating solar and IR cloud forcing of net radiation at the surface. Three sources of data are used: ESRL direct measurements from the ship, NOAA/ PMEL direct measurements from the TAO buoys, and satellite estimates from the International Satellite Cloud Climatology Project (ISCCP). These have been compared to ERA-40 and NCEP-2 reanalysis products. Details on the TAO, ISCCP, and reanalysis products are given in Cronin et al. (2006b). The ESRL radiative flux instruments are tended daily and are considered to have the best absolute accuracy. However, their temporal sampling is poor (a few days at each latitude bin each transect). Averaging over multiple cruises reduces the sampling errors, but the TAO buoys are still superior in this respect. Because the buoy sensors are unattended for six month intervals, their absolute calibration is more problematic. The accuracy of the buoy measurements has been assessed by comparing with the ESRL measurements in Cronin et al. (2006b). Paradoxically, the practicalities of replacing the buoys results in very little direct intercomparison with shipbased sensors while the ship is close to the buoy (proximity is critical for radiative flux comparisons). The satellite data have good temporal sampling (essentially continuous), but must be considered an indirect measurement.

The result of a comparison of these data is shown in Fig. 16. The "measurements" are indicated with thin dotted lines and the two NWP products with heavy dashed lines. A consensus estimate based on the three measurement sets is indicated by the dark red line. The fall data show a strong ITCZ at about $6^{\circ} \mathrm{N}$; the spring has a weaker double ITCZ signature. The buoy solar SCF tends to be about $20 \mathrm{~W} \mathrm{~m}^{-2}$ more negative than the ESRL and ISCCP data, but the significance is unknown so we have treated the three sets as equivalent. The standard deviations of the individual measurement sets (after averaging over latitude) from the consensus is $3 \mathrm{~W} \mathrm{~m}^{-2}$ for IR and $11 \mathrm{~W} \mathrm{~m}^{-2}$ for solar SCF. Solar SCF is about three times greater than IR, consistent with the larger standard deviation.

For IR SCF the latitudinal averages of NWP and observational data are essentially indistinguishable. Neither NWP product diagnoses the observed enhancement in IR SCF at the ITCZ with the exception of the ERA-40 for the ITCZ north of the equator in spring. For solar SCF, both NWP products have errors exceeding $30 \mathrm{~W} \mathrm{~m}^{-2}$. In spring the latitude-averaged bias is $32 \mathrm{~W} \mathrm{~m}^{-2}$ for ERA-40 and $60 \mathrm{~W} \mathrm{~m}^{-2}$ for NCEP-2 (i.e., the NWP products have too much cloud or their clouds are too dark). ERA-40 overemphasizes the ITCZ; NCEP-2 gets the latitudinal structure completely wrong. In fall the latitude-averaged bias is $8 \mathrm{~W} \mathrm{~m}^{-2}$ for ERA-40 and $45 \mathrm{~W} \mathrm{~m}^{-2}$ for NCEP-2. Here ERA-40 is better, but still gets too much SCF in the ITCZ. It is puzzling that the latitudinal structures in the NWP products are so much more prominent in the solar SCF than in the IR SCF. The implication is that they are handling the deep clouds in the ITCZ considerably better than the MBL clouds since higher clouds do not affect the IR SCF. This is probably a manifestation of the longstanding problem of representing MBL clouds in GCMs (Randall et al. 1985; Teixeira and Hogan 2002).

\section{Conclusions}

We have produced a unique analysis of air-sea flux and cloud measurements from a series of seven cruises made in the eastern equatorial Pacific between fall 1999 and fall 2002 along the enhanced TAO buoy lines along $95^{\circ}$ and $110^{\circ} \mathrm{W}$ longitudes. Our analysis emphasized the statistical properties as a function of latitude contrasting the Northern Hemisphere fall and spring seasons. The direct observations of boundary layer and cloud properties of study complement the purely buoy-based annual cycle observations of Cronin et al. (2006a,b) and our emphasis on cloud properties and fluxes contrasts with the study of MBL structure in the region of Pyatt et al. (2005). Siebesma et al. (2004) presented a comparison of nine weather and climate models to satellitebased observations along a NW-SE transect from the California coast $\left(35^{\circ} \mathrm{N}\right)$ to the date line at the equator. Their transect essentially avoided the cold tongue, their 
(a)

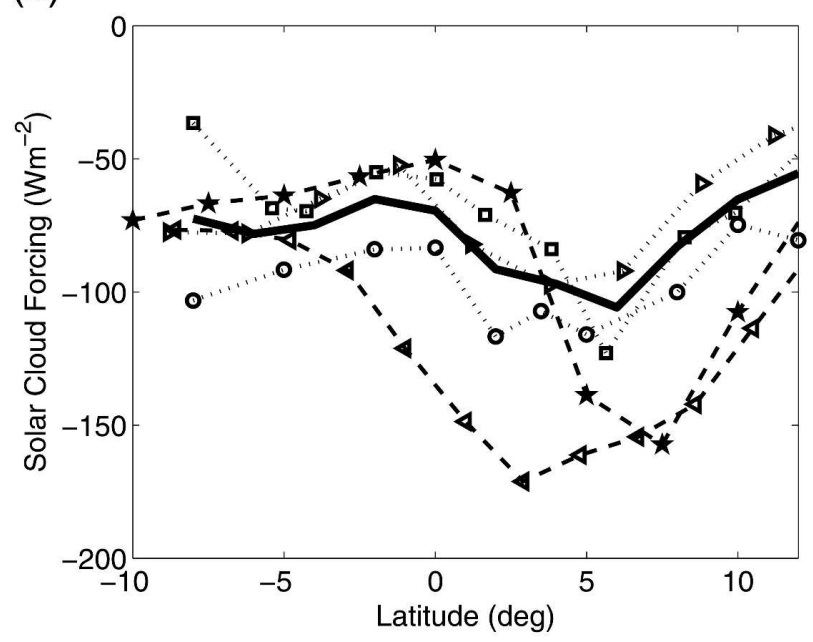

(c)

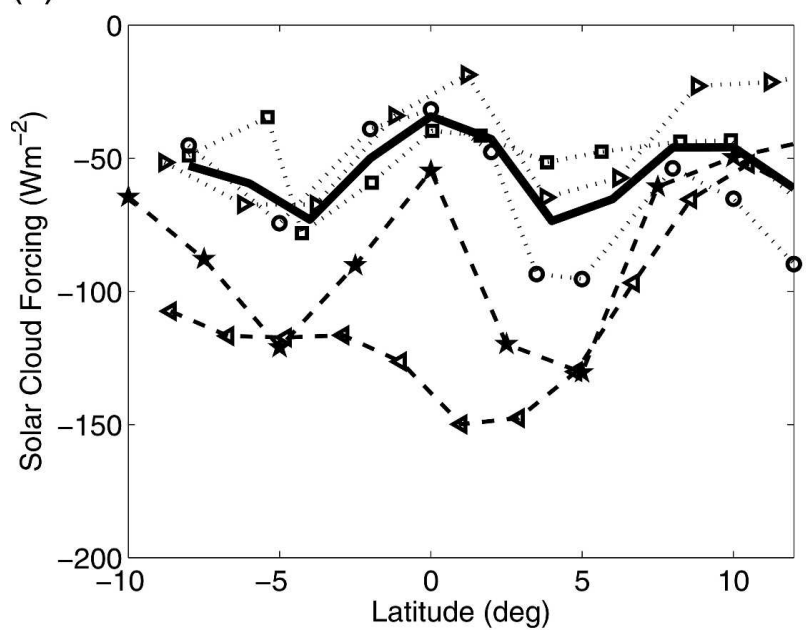

(b)

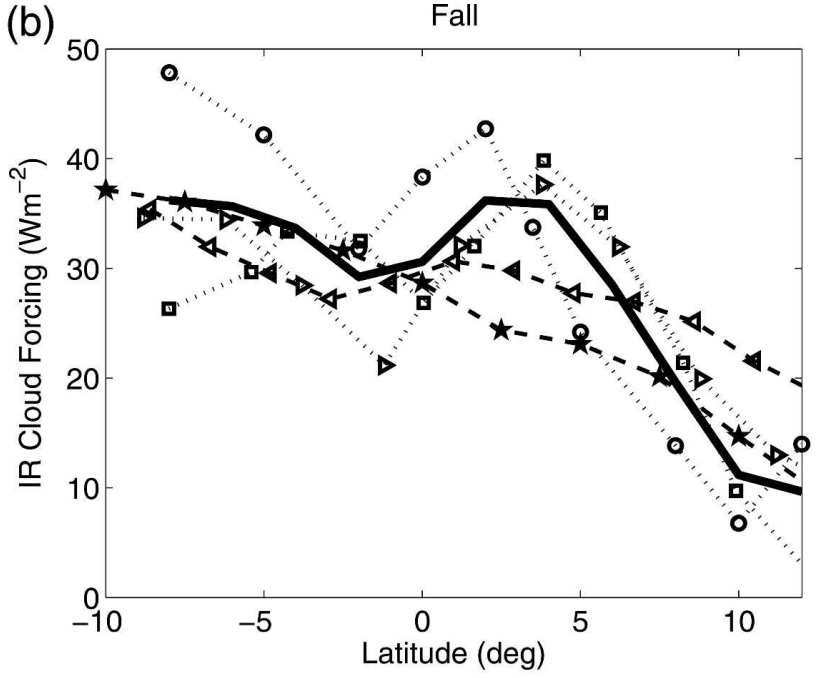

(d)

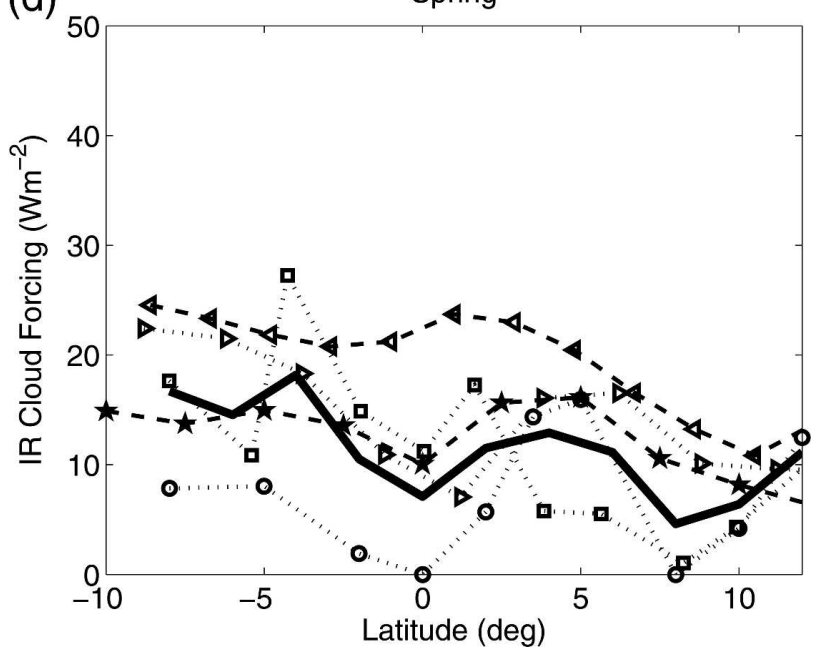

FIG. 16. Cloud forcing as a function of latitude averaged of the spring and fall PACS cruises near the equator in the east Pacific: (a) fall solar SCF, (b) fall IR SCF, (c) spring solar SCF, and (d) spring IR SCF. The measurements are for TAO buoys (circle), ESRL ship data (square), ISCCP (right pointing open triangle), and mean of these three (heavy solid line). The symbols for the reanalysis products are NCEP-2: left-pointing triangle, and ERA-40: star. ESRL data are computed from cruise averages; buoy, satellite, and NWP are computed from monthly averages in the cruise season window.

estimates of surface solar radiative fluxes only extended to $5^{\circ} \mathrm{N}$, surface IR radiative flux was not examined, turbulent fluxes were based on reanalyses and the daSilva climatology, and their analysis was limited to June-August (JJA). The repeated observations of our study provide estimates of interannual variability, a key difference to studies based on single cruises (e.g., White et al. 1995; Post et al. 1997; Bretherton et al. 2004).

The most obvious seasonal differences are the stronger Northern Hemisphere ITCZ and stronger northsouth SST difference in the fall periods. Much stronger turbulent heat fluxes occur in the SST frontal region north of the equator in the fall associated with southeasterly cross-equatorial airflow. Colder water south of the equator in fall exerts a strong cooling influence on the ocean north of the equator (through sensible and latent heat fluxes combined, an additional $55 \mathrm{~W} \mathrm{~m}^{-2}$ compared to spring). The well-defined ITCZ region north of the equator in the fall also produces much more cloudiness, precipitation, southerly winds, and solar cloud forcing in the region around $6^{\circ} \mathrm{N}$.

We examined cloud fraction, cloud-base height statistics, and cloudy liquid water path. The spring clouds showed a significant diurnal variation with substantially lower cloud fraction during the day south of $5^{\circ} \mathrm{N}(\mathrm{ex}-$ cept in the southern ITCZ region at $4^{\circ} \mathrm{S}$ ), while no diurnal variation was observed in fall. The spring diurnal behavior is consistent with satellite cloud liquid 
water observations (Wood et al. 2002). By considering the peak in the cloud base distribution (i.e., the most probable cloud base height), we demonstrated the significant effects on clouds near the equator. The lower cloud bases near the equator reflect cooling as air from south of the equator flows over the cold tongue, stabilizing the lower MBL and decoupling the upper MBL from the surface. The equatorial effects were stronger in the fall when the cold tongue is much colder.

Surface cloud-radiative forcing (SCF) is defined as the difference in mean observed net radiative flux and that flux which would be observed in the absence of clouds. For IR fluxes, SCF strongly correlates with cloud fraction on daily time scales. There are substantial seasonal differences in IR SCF but relatively modest seasonal differences in maximum cloud forcing (MSCF, $53 \mathrm{~W} \mathrm{~m}^{-2}$ in the fall versus $40 \mathrm{~W} \mathrm{~m}^{-2}$ in spring). For solar fluxes, MSCF is about $-135 \mathrm{~W} \mathrm{~m}^{-2}$. The large seasonal differences in solar SFC (Fig. 11) are principally due to differences in cloud fraction, except for the ITCZ where the fall has significantly larger cloudy liquid water path. When radiative properties are averaged in cloud fraction bins, the fall versus spring differences are fairly small (Fig. 15). The $f=1.0$ intercepts of the fits in Fig. 15 yield an estimate of the ratio of mean solar to IR MSCF $(-135 / 53=-2.5)$, which implies that clouds in this region strongly cool the surface (although less than that of the tropical western Pacific).

SCF was examined further by comparing observations with NWP reanalysis. The ESRL means were combined with buoy and satellite monthly averages of SCF for fall and spring to obtain a consensus estimate based on measurements. The individual data sources agreed within about $10 \mathrm{~W} \mathrm{~m}^{-2}$ with the consensus values. The reanalysis products were within $10 \mathrm{~W} \mathrm{~m}^{-2}$ of the observations for IR SCF but substantially overestimated the solar SCF, particularly in spring. The inconsistent behavior of the reanalysis products (IR versus solar) suggests the models are generating incorrect distributions of cloud types (see Cronin et al. 2006a for further discussion).

Finally, the contributions of clouds to the net surface heat budget are shown in Fig. 17. The latitudinal distribution of the net heat flux (upper panel) shows a striking difference between the spring and fall. The spring net heat flux is nearly symmetrical about the equator with a maximum $\left(175 \mathrm{~W} \mathrm{~m}^{-2}\right)$ at the equator decreasing to about $100 \mathrm{~W} \mathrm{~m}^{-2}$ at $10^{\circ} \mathrm{N}$ and $8^{\circ} \mathrm{S}$. Because the net SFC in spring is almost independent of latitude, the equatorial maximum is associated with a minimum in turbulent fluxes at the equator. In the fall, the maximum net heat flux $\left(180 \mathrm{~W} \mathrm{~m}^{-2}\right)$ is at $2^{\circ} \mathrm{S}$ and the mini-
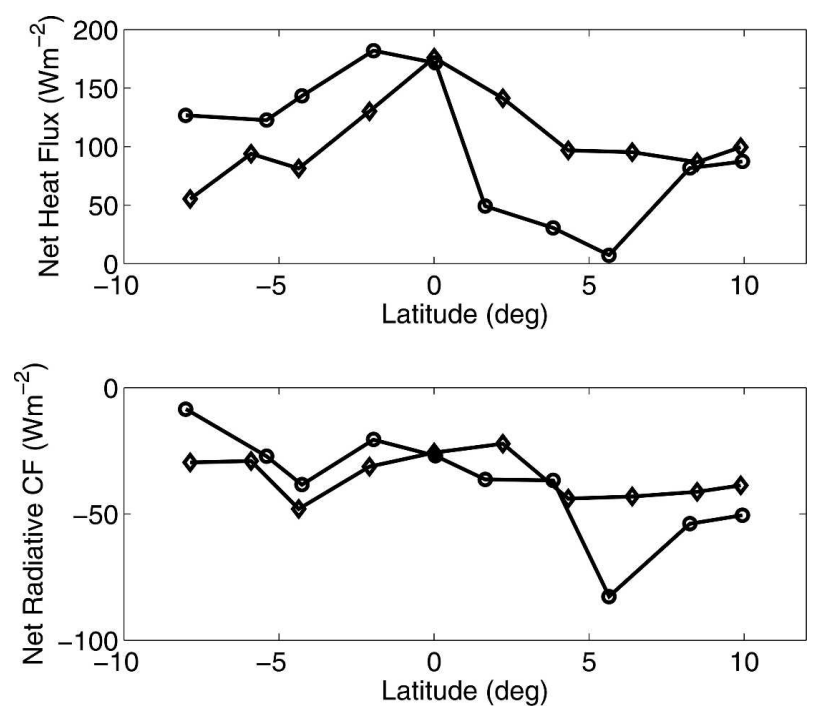

FIG. 17. Latitude-averaged surface fluxes. (top) Net heat flux into the ocean and (bottom) contribution to the net heat flux accounted for by SCF (circles: fall; diamonds: spring).

mum (essentially 0 ) is at $6^{\circ} \mathrm{N}$. There is also a significant asymmetry away from the equator $\left(125 \mathrm{~W} \mathrm{~m}^{-2}\right.$ at $8^{\circ} \mathrm{S}$ versus $75 \mathrm{~W} \mathrm{~m}^{-2}$ at $\left.10^{\circ} \mathrm{N}\right)$. Clearly, the minimum SCF at $6^{\circ} \mathrm{N}$ is primarily associated with strong solar SCF (lower panel in Fig. 16) associated with the ITCZ. The maximum just south of the equator is associated with much weaker turbulent cooling (Fig. 5) and weaker solar SCF. Solar SCF is also much more equatorially asymmetric in the fall (Fig. 17).

Acknowledgments. This work was supported by the NOAA/Office of Global Programs, ONR Marine Meteorology program, the DOE Atmospheric Radiation Measurement program, and the National Science Foundation Climate Dynamics program. The authors especially thank Scott Abbott, Dave Costa, Mike Falls, Dan Gottas, Jim Jordan, Jesse Leach, Brenda Mulac, Jeff Otten, Bill Otto, Sergio Pezoa, Michelle Ratterree, Cat Russell, Kara Sterling, and Dan Wolfe for work, dedication, and personal sacrifice in doing the field work. The contributions and help of the crews of the NOAA ships Ronald H. Brown and Ka'imimoana is greatly appreciated. Comments from two anonymous reviewers we used to improve the manuscript.

\section{APPENDIX A}

\section{Clear-Sky Radiative Flux Parameterizations}

For the study of SCF, the realization of the fluxes at the air-surface interface can be handled effectively by simple methods (e.g., Lind et al. 1984; Katsaros 1990; 
Key et al. 1996). For one thing, we only require estimates of clear-sky flux because the all-sky flux is directly measured. Furthermore, we can accommodate regional and seasonal variability by tuning the model to fit the observations during clear periods. For this approach, the challenge is to plainly identify the clear periods. To do that, we use estimates of the vertical cloud fraction from the ceilometer data. More detail on this process can be found in Hare et al. (2005).

\section{a. IR flux}

Most IR parameterizations estimate the flux in terms of near-surface parameters such as air temperature, $T_{a}$ :

$$
R_{\mathrm{ld}}=\varepsilon_{e} \sigma T_{a}^{4}
$$

where $\varepsilon_{e}$ is an effective total-sky emissivity that, when combined with the air temperature, yields an estimate of the IR flux. For clear-sky conditions, $\varepsilon_{e}$ is an empirical function of atmospheric water vapor contenteither local humidity, $q_{a}$, or the total integrated column water vapor, IV. Josey et al. (2003) offer a variation using $T_{a}$ and dewpoint temperature depression, and Garratt (2001) presents another utilizing $T_{a}$ and IV (see Table 2 for units of these variables).

We have chosen the Brunt (1932) form for the parameterization of effective emissivity for clear skies, $\varepsilon_{e 0}$ :

$$
\varepsilon_{e 0}=A+B \sqrt{q_{a}} .
$$

Using the ESRL ship-based radiative flux observations from 15 campaigns (Fairall et al. 2003), we have previously determined the $A$ and $B$ coefficients as simple linear functions of latitude. This fit is based on data obtained between the equator and $60^{\circ} \mathrm{N}$, but the majority of the data were obtained within $15^{\circ}$ of the equator. For this study, we optimized the fit using only data from the PACS cruises within $15^{\circ}$ of the equator. This gives a result:

$$
\left.A=0.50+\frac{0.13}{60} \text { abs(lat) } \quad B=0.091-\frac{0.03}{60} \text { abs(lat }\right) .
$$

We also added IV for a three-parameter fit. The IV was obtained through retrieval of surface-based microwave radiance. Adding the column water vapor gives a fit of the form

$$
\varepsilon_{e 0}=A+B \sqrt{q_{a}}-0.0188+0.0063 \mathrm{IV} .
$$

Slight adjustments in the latitude dependences are required to provide a better fit when using column water vapor in this expression. The fits are based on approxi-

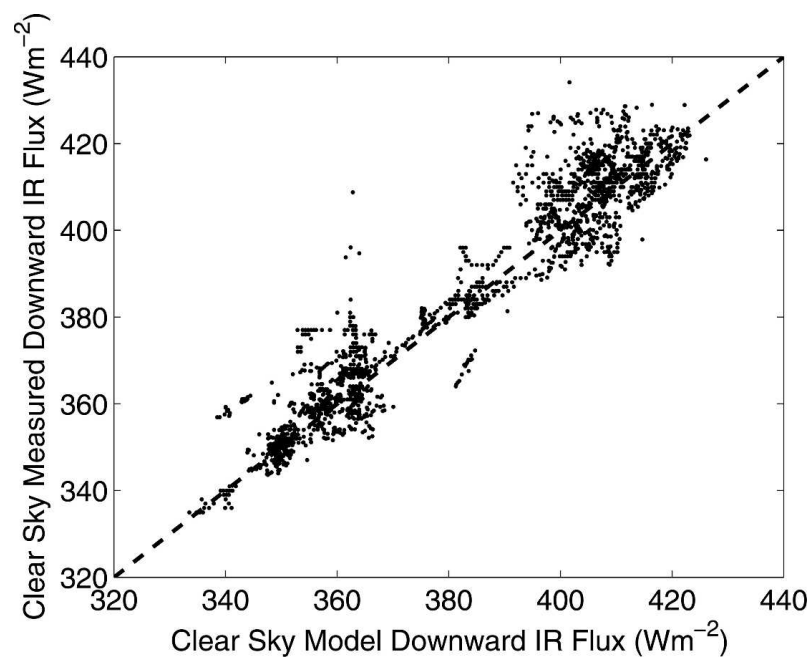

FIG. A1. Comparison of clear-sky IR fluxes using model ( $x$ axis) from Eqs. (4)-(5) and measurements ( $y$ axis) for 60-min cloudfree periods.

mately 2300 10-min observations (out of a total of 22127 observations within $15^{\circ}$ of the equator with simultaneous column water vapor measurements). Clear skies were diagnosed by requiring zero cloud fraction from $25 \mathrm{~min}$ before to $25 \mathrm{~min}$ after the observation time.

Figure A1 shows measurements and two-parameter model values of downward IR flux for periods when the ceilometer-measured cloud fraction is 0 for a continuous 60-min time period. Individual points well above the line are caused by clouds in the field of view of the IR radiometer but are not directly above the ceilometer. We also computed the residuals between the measured data and the model as a function of the column water vapor. A linear fit of these residuals (with a few small adjustments to $A$ and $B$ ) was used to obtain the three-parameter model. The two-parameter fit has a bias of $-1.8 \mathrm{~W} \mathrm{~m}^{-2}$ and a standard deviation of 7 $\mathrm{W} \mathrm{m}{ }^{-2}$, whereas the three-parameter fit has a bias of $-0.9 \mathrm{~W} \mathrm{~m}^{-2}$ and a standard deviation of $5.7 \mathrm{~W} \mathrm{~m}^{-2}$.

\section{b. Solar flux}

We are using the solar flux parameterization from Iqbal (1988), which contains components to track the angular position of the sun as a function of day of the year, time of day, and latitude. The solar flux constant at the top of the atmosphere is set to $1367 \mathrm{~W} \mathrm{~m}^{-2}$, and the transmission coefficient of the atmosphere is estimated from specifications of total column ozone, aerosol optical thickness in two wave bands, and the column integrated water vapor IV as above. We then tune the model by plotting the time series of measured $R_{s d}$ and comparing it to computed clear-sky values from the 
algorithm. The aerosol values are then adjusted to fit the peak solar flux for clear days on a cruise-by-cruise basis. We find that slightly different aerosol coefficients are required in the fall versus the spring.

We have examined the accuracy of this method by computing the probability distribution of the measured-modeled difference in solar flux for cases where the solar zenith angle is less than $20^{\circ}$ and cloud fraction is zero (471 samples meet these conditions). The peak of this distribution occurs at $0 \mathrm{~W} \mathrm{~m}^{-2}$ (i.e., no model bias) and has a half-width at half-maximum (an estimate of the standard deviation) of $20 \mathrm{~W} \mathrm{~m}^{-2}$. Because some of this width is caused by cloud reflections and random variability in the measurements, we estimate the standard deviation of the model near the solar peak to be $15 \mathrm{~W} \mathrm{~m}^{-2}$ with a model bias of about $-5 \mathrm{~W} \mathrm{~m}^{-2}$. For daily average solar fluxes where measurements of column water vapor are available, these values correspond to a model bias of $-2 \mathrm{~W} \mathrm{~m}^{-2}$ and a standard deviation of $5 \mathrm{~W} \mathrm{~m}^{-2}$.

The bias and variability quoted for the clear-sky models are not absolute accuracies, but are computed relative to the data from which they are tuned. We are concerned with the mean measured flux minus the mean clear-sky modeled flux. Because we have tuned the model to the data that we are analyzing, biases in the measurements will, to first order, cancel in the computation of SCF. For daily average values, the uncertainty in SCF will be about $5-7 \mathrm{~W} \mathrm{~m}^{-2}$ for both IR and solar fluxes.

\section{APPENDIX B}

\section{List of Acronyms}

CCM3 Community Climate Model (version 3)

CLIVAR Climate Variability and Predictability program

ECMWF European Centre for Medium-Range Weather Forecasts

ENSO El Niño-Southern Oscillation

EPIC Eastern Pacific Investigation of Climate Processes in the Coupled OceanAtmosphere System

EPIC2001 A major field study held in fall 2001 as part of the EPIC program

ERA-40 40-yr ECMWF Re-Analysis

ESRL Earth System Research Laboratory

GCM General circulation model

IR Atmospheric radiative flux in the infrared band

ISCCP International Satellite Cloud Climatology Project
ITCZ Intertropical convergence zone

KA NOAA ship Ka'imimoana

LW Longwave atmospheric radiative flux (same as IR)

MBL Marine boundary layer

NCEP-2 National Centers for Environmental Prediction Second Reanalysis

NPCO NOAA Portable Cloud Observatory (seagoing cloud observing system)

NWP Numerical weather prediction

PACS Pan-American Climate Studies (NOAA research program)

PMEL Pacific Marine Environmental Laboratory

$R B \quad$ NOAA ship Ronald H. Brown

SST Sea surface temperature

SW Atmospheric radiative flux in the solar band

TAO Tropical Atmosphere Ocean buoy observations

TRRM Tropical Rainfall Measuring Mission (NASA rainfall satellite)

WHOI Woods Hole Oceanographic Institution

\section{APPENDIX C}

\section{List of Symbols}

$f$

Cloud fraction (averaged vertical cloud occurrence)

lat Latitude (degrees)

$q \quad$ Specific humidity $\left(\mathrm{g} \mathrm{kg}^{-1}\right)$

cloud $f$ Cloud fraction (averaged vertical cloud occurrence), same as $f$

cloud_s $f$ Daytime cloud fraction

Rain Rain rate $\left(\mathrm{mm} \mathrm{day}^{-1}\right)$

$z_{b} \quad$ Cloud-base height (m)

$z_{b} 15 \% \quad$ Cloud-base height where $15 \%$ of clouds are lower $(15 \%$ point in the cumulative probability distribution)

$z_{b}$ peak Cloud-base height from a peak in the probability distribution

CF Cloud radiative forcing, mean flux - clearsky flux $\left(\mathrm{W} \mathrm{m}^{-2}\right)$

$H_{s} \quad$ Sensible heat flux $\left(\mathrm{W} \mathrm{m}^{-2}\right)$

$H_{l} \quad$ Latent heat flux $\left(\mathrm{W} \mathrm{m}^{-2}\right)$

IV Integrated atmospheric water vapor $(\mathrm{cm})$

MCF Maximum cloud forcing, overcast fluxclear-sky flux $\left(\mathrm{W} \mathrm{m}^{-2}\right)$

$R_{\mathrm{ld}} \quad$ Downward IR radiative flux ( $\mathrm{W} \mathrm{m}^{-2}$ )

$R_{\text {lcl }} \quad$ Clear-sky downward IR radiative flux $\left(\mathrm{W} \mathrm{m}^{-2}\right.$ )

$R_{\text {lnet }} \quad$ Net (downward - upward) IR radiative flux $\left(\mathrm{W} \mathrm{m}^{-2}\right)$

$R_{\mathrm{sd}} \quad$ Downward solar radiative flux $\left(\mathrm{W} \mathrm{m}^{-2}\right)$ 
$R_{\text {scl }} \quad$ Clear-sky downward solar radiative flux $\left(\mathrm{W} \mathrm{m}^{-2}\right)$

$S \quad$ Wind speed $\left(\mathrm{m} \mathrm{s}^{-1}\right)$

$T_{a} \quad$ Air temperature $\left({ }^{\circ} \mathrm{C}\right)$

$T_{s} \quad$ Sea surface temperature (C)

Trans_sol Solar radiative transfer coefficient $\left(R_{\mathrm{sd}} / R_{\mathrm{scl}}\right)$

$U_{e} \quad$ Eastward wind component $\left(\mathrm{m} \mathrm{s}^{-1}\right)$

$U_{n} \quad$ Northward wind component $\left(\mathrm{m} \mathrm{s}^{-1}\right)$

$W \quad$ Integrated cloud liquid water $\left(\mathrm{g} \mathrm{m}^{-2}\right)$

$W_{\text {cld }} \quad$ Integrated cloud liquid water when clouds are present $\left(\mathrm{g} \mathrm{m}^{-2}\right)$

$W_{\text {cld_s }} \quad$ Solar flux-weighted integrated cloud liquid water when clouds are present $\left(\mathrm{g} \mathrm{m}^{-2}\right)$

$\alpha \quad$ Albedo of the sea surface (0.055)

\section{REFERENCES}

Albrecht, B. A., M. P. Jensen, and W. J. Syrett, 1995: Marine boundary layer structure and fractional cloudiness. J. Geophys. Res., 100, 14 209-14 222.

Bond, N. A., 1992: Observations of planetary boundary-layer structure in the eastern equatorial Pacific. J. Climate, 5, 699706.

Bretherton, C. S., and Coauthors, 2004: The EPIC 2001 stratocumulus study. Bull. Amer. Meteor. Soc., 85, 967-977.

Browning, K. A., 1994: Survey of perceived priority issues in the parametrizations of cloud-related processes in GCMs. Quart. J. Roy. Meteor. Soc., 120, 483-487.

Brunt, D., 1932: Notes on radiation in the atmosphere. Quart. J. Roy. Meteor. Soc., 58, 389-420.

Cess, R. D., and Coauthors, 1995: Absorption of solar radiation by clouds: Observations versus models. Science, 267, 496-499.

Collins, W. D., J. Wang, J. T. Kiehl, G. J. Zhang, D. I. Cooper, and W. E. Eichinger, 1997: Comparison of tropical oceanatmosphere fluxes with the NCAR Community Climate Model CCM3. J. Climate, 10, 3047-3058.

Cronin, M. F., N. Bond, C. W. Fairall, J. E. Hare, M. J. McPhaden, and R. A. Weller, 2002: Enhanced oceanic and atmospheric monitoring underway in Eastern Pacific. Eos, Trans. Amer. Geophys. Union, 83, 205-211.

—, N. A. Bond, C. W. Fairall, and R. A. Weller, 2006a: Surface cloud forcing in the east Pacific stratus deck/cold tongue/ ITCZ complex. J. Climate, 19, 392-409.

— C. W. Fairall, and M. J. McPhaden, 2006b: An assessment of buoy-derived and numerical weather prediction surface heat fluxes in the tropical Pacific. J. Geophys. Res., 111, C06038, doi:10.1029/2005JC003324.

Delecluse, P., M. K. Davey, Y. Kitamura, S. G. H. Philander, M. Suarez, and L. Bengtsson, 1998: Coupled general circulation modeling of the tropical Pacific. J. Geophys. Res., 103, 14 357-14 374.

de Szoeke, S. P., C. S. Bretherton, N. A. Bond, M. F. Cronin, and B. M. Morley, 2005: EPIC $95^{\circ} \mathrm{W}$ observations of the eastern Pacific atmospheric boundary layer from the cold tongue to the ITCZ. J. Atmos. Sci., 62, 426-442.

Fairall, C. W., E. F. Bradley, J. S. Godfrey, G. A. Wick, J. B. Edson, and G. S. Young, 1996: Cool-skin and warm-layer effects on sea surface temperature. J. Geophys. Res., 101, 1295-1308.

_ - A. B. White, J. B. Edson, and J. E. Hare, 1997: Integrated shipboard measurements of the marine boundary layer. $J$. Atmos. Oceanic Technol., 14, 338-359.

- E. F. Bradley, J. E. Hare, A. A. Grachev, and J. B. Edson, 2003: Bulk parameterization of air-sea fluxes: Updates and verification for the COARE algorithm. J. Climate, 16, 571591.

Garratt, J. R., 2001: Clear-sky longwave irradiance at the Earth's surface-Evaluation of climate models. J. Climate, 14, 16471670.

_ and A. J. Prata, 1996: Downwelling longwave fluxes at continental surfaces-A comparison of observations with GCM simulations and implications for the global land-surface radiation budget. J. Climate, 9, 646-655.

Gleckler, P. J., K. R. Sperber, and K. Achuta Rao, 2006: Annual cycle of global ocean heat content: Observed and simulated. J. Geophys. Res., 111, C06008, doi:10.1029/2005JC003223.

Grant, A. L. M., and P. Hignett, 1998: Aircraft observations of the surface energy balance in TOGA-COARE. Quart. $J$. Roy. Meteor. Soc., 124, 101-122.

Hare, J. E., C. W. Fairall, T. Uttal, D. Hazen, M. F. Cronin, N. A. Bond, and D. Veron, 2005: Cloud, radiation, and surface forcing in the equatorial eastern Pacific. NOAA Tech. Memo. OAR-PSD 307, NOAA/ESRL, Boulder, CO, 64 pp. [Available online at ftp://ftp.etl.noaa.gov/user/cfairall/EPIC/ epicmonitor/techmemo/.]

Hartmann, D. L., M. E. Ockert-Bell, and M. L. Michelsen, 1992: The effect of cloud type on Earth's energy balance: Global analysis. J. Climate, 5, 1281-1304.

Hashizume, H., S.-P. Xie, M. Fujiwara, M. Shiotani, T. Watanabe, Y. Tanimoto, W. T. Liu, and K. Takeuchi, 2002: Direct observations of atmospheric boundary layer response to SST variations associated with tropical instability waves over the eastern equatorial Pacific. J. Climate, 15, 3379-3393.

Intrieri, J. M., C. W. Fairall, M. D. Shupe, P. O. G. Persson, E. L. Andreas, P. S. Guest, and R. E. Moritz, 2002: An annual cycle of Arctic surface cloud forcing at SHEBA. J. Geophys. Res., 107, 8039, doi:10.1029/2000JC000439.

Iqbal, M., 1988: Spectral and total sun radiance under cloudless skies. Physical Climatology for Solar and Wind Energy, R. Guzzi and C. G. Justus, Eds., World Scientific, 196-242.

Josey, S. A., R. W. Pascal, P. K. Taylor, and M. J. Yelland, 2003: A new formula for determining the atmospheric longwave flux at the ocean surface at mid-high latitudes. J. Geophys. Res., 108, 3108, doi:10.1029/2002JC001418.

Katsaros, K. B., 1990: Parameterization schemes and models for estimating the surface radiation budget. Remote Sensing, G. L. Geernaert and W. J. Plant, Eds., Vol. II, Surface Waves and Fluxes, Kluwer Academic, 339-368.

Key, J. R., R. A. Silcox, and R. S. Stone, 1996: Evaluation of surface radiative flux parameterizations for use in sea ice models. J. Geophys. Res., 101, 3839-3850.

Large, W. G., and G. Danabasoglu, 2006: Attribution and impacts of upper-ocean biases in CCSM3. J. Climate, 19, 2325-2346.

Li, T., and S. G. H. Philander, 1996: On the annual cycle of the eastern equatorial Pacific. J. Climate, 9, 2986-2998.

Lind, R. J., K. B. Katsaros, and M. Gube, 1984: Radiation budget components and their parametrization in JASIN. Quart. $J$. Roy. Meteor. Soc., 110, 1061-1071.

Ma, C.-C., C. R. Mechoso, A. W. Robertson, and A. Arakawa, 1996: Peruvian stratus clouds and the tropical Pacific circulation: A coupled ocean-atmosphere GCM study. J. Climate, 9, 1635-1645.

Mechoso, C. R., and Coauthors, 1995: The seasonal cycle over the 
tropical Pacific in coupled ocean-atmosphere general circulation models. Mon. Wea. Rev., 123, 2825-2838.

Menon, S., A. D. Del Genio, D. Koch, and G. Tselioudis, 2002: GCM simulations of the aerosol indirect effect: Sensitivity to cloud parameterization and aerosol burden. J. Atmos. Sci., 59, 692-713.

Miller, M. J., A. C. M. Beljaars, and T. N. Palmer, 1992: The sensitivity of the ECMWF model to the parameterization of evaporation from the tropical oceans. J. Climate, 5, 418-434.

Moran, K. P., B. E. Martner, M. J. Post, R. A. Kropfli, D. C. Welsh, and K. B. Widener, 1998: An unattended cloudprofiling radar for use in climate research. Bull. Amer. Meteor. Soc., 79, 443-455.

Norris, J. R., and C. B. Leovy, 1994: Interannual variability in stratiform cloudiness and sea surface temperature. J. Climate, 7, 1915-1925.

Philander, S. G. H., D. Gu, D. Halpern, G. Lambert, N.-C. Lau, T. Li, and R. C. Pacanowski, 1996: Why the ITCZ is mostly north of the equator. J. Climate, 9, 2958-2972.

Phillips, T. J., and Coauthors, 2006: Coupled climate model appraisal: A benchmark for future studies. Eos, Trans. Amer. Geophys. Union, 87, 185.

Pincus, R., M. B. Baker, and C. S. Bretherton, 1997: What controls stratocumulus radiative properties? Lagrangian observations of cloud evolution. J. Atmos. Sci., 54, 2215-2236.

Post, M. J., and Coauthors, 1997: The Combined Sensor Program: An air-sea science mission in the central and western Pacific Ocean. Bull. Amer. Meteor. Soc., 78, 2797-2815.

Pyatt, H. E., B. A. Albrecht, C. W. Fairall, J. E. Hare, N. A. Bond, P. Minnis, and J. K. Ayers, 2005: Evolution of marine atmospheric boundary layer structure across the cold tongueITCZ complex. J. Climate, 18, 737-753.

Ramanathan, V., R. D. Cess, E. F. Harrison, P. Minnis, B. R. Barkstrom, E. Ahmad, and D. Hartmann, 1989: Cloudradiative forcing and climate: Results from the Earth Radiation Budget Experiment. Science, 243, 57-63.

, B. Subasilar, G. J. Zhang, W. Conant, R. D. Cess, J. T. Kiehl, H. Grassl, and L. Shi, 1995: Warm pool heat budget and shortwave cloud forcing: A missing physics? Science, 267, 499-503.

Randall, D. A., J. A. Abeles, and T. G. Corsetti, 1985: Seasonal simulations of the planetary boundary layer and boundarylayer stratocumulus clouds with a general circulation model. J. Atmos. Sci., 42, 641-676.

Raymond, D. J., and Coauthors, 2004: EPIC2001 and the coupled ocean-atmosphere system of the tropical east Pacific. Bull. Amer. Meteor. Soc., 85, 1341-1354.

Rozendaal, M. A., C. B. Leovy, and S. A. Klein, 1995: An observational study of diurnal variations of marine stratiform cloud. J. Climate, 8, 1795-1809.

Siebesma, A. P., and Coauthors, 2004: Cloud representation in general-circulation models over the northern Pacific Ocean: A EUROCS intercomparison study. Quart. J. Roy. Meteor. Soc., 130, 3245-3267.
Snider, J. B., and D. A. Hazen, 1998: Surface-based radiometric observations of water vapor and cloud liquid in the temperate zone and in the tropics. Radio Sci., 33, 421-432.

Stephens, G. L., and P. J. Webster, 1981: Clouds and climate: Sensitivity of simple systems. J. Atmos. Sci., 38, 235-247.

Teixeira, J., and T. F. Hogan, 2002: Boundary layer clouds in a global atmospheric model: Simple cloud cover parameterizations. J. Climate, 15, 1261-1276.

Tian, B., and V. Ramanathan, 2002: Role of tropical clouds in surface and atmospheric energy budget. J. Climate, 15, 296305.

U.S. CLIVAR Pan American Implementation Panel, 2002: U.S. CLIVAR Pan American Research: A scientific prospectus and implementation plan. U.S. CLIVAR Office, Washington, DC, $58 \mathrm{pp}$.

Walsh, J. E., and W. L. Chapman, 1998: Arctic cloud-radiationtemperature associations in observational data and atmospheric reanalyses. J. Climate, 11, 3030-3045.

Wang, W., S. Saha, H.-L. Pan, S. Nadiga, and G. White, 2005: Simulation of ENSO in the new NCEP coupled forecast system model (CFS03). Mon. Wea. Rev., 133, 1574-1593.

Weller, B., and Coauthors, 1999: A science and implementation plan for EPIC: An eastern Pacific investigation of climate processes in the coupled ocean-atmosphere system. $105 \mathrm{pp}$. [Available online at http:://www.atmos.washington.edu/gcg/ EPIC/.]

Weng, F., N. C. Grody, R. Ferraro, A. Basist, and D. Forsyth, 1997: Cloud liquid water climatology from the Special Sensor Microwave Imager. J. Climate, 10, 1086-1098.

White, A. B., C. W. Fairall, and J. B. Snider, 1995: Surface-based remote sensing of marine boundary-layer cloud properties. J. Atmos. Sci., 52, 2827-2838.

,-- A. S. Frisch, B. W. Orr, and J. B. Snider, 1996: Recent radar measurements of turbulence and microphysical parameters in marine boundary layer clouds. Atmos. Res., 40, 177221

Wild, M., A. Ohmura, H. Gilgen, and E. Roeckner, 1995: Validation of general circulation model radiative fluxes using surface observations. J. Climate, 8, 1309-1324.

Wittenberg, A. T., A. Rosati, N.-C. Lau, and J. J. Ploshay, 2006: GFDL's CM2 global coupled climate models. Part III: Tropical Pacific climate and ENSO. J. Climate, 19, 698-722.

Wood, R., C. S. Bretherton, and D. L. Hartmann, 2002: Diurnal cycle of liquid water path over the subtropical and tropical oceans. Geophys. Res. Lett., 29, 2092, doi:10.1029/ 2002 GL015371.

Yuter, S. E., and R. A. Houze Jr., 2000: The 1997 Pan American Climate Studies Tropical Eastern Pacific Process Study. Part I: ITCZ region. Bull. Amer. Meteor. Soc., 81, 451-481.

- , and W. S. Parker, 2001: Rainfall measurement on ship revisited: The 1997 PACS TEPPS cruise. J. Appl. Meteor., 40, 1003-1018. 